\title{
Combining Facility Location and Routing Decisions in Sustainable Urban Freight Distribution under Horizontal Collaboration: How Can Shippers Be Benefited?
}

\author{
Hanan Ouhader and Malika El Kyal \\ Laboratory of Industrial and Computing Engineering, National School of Applied Sciences, Ibn Zohr University, Agadir, Morocco \\ Correspondence should be addressed to Hanan Ouhader; ouhader@gmail.com
}

Received 6 December 2016; Revised 30 March 2017; Accepted 27 April 2017; Published 5 July 2017

Academic Editor: Purushothaman Damodaran

Copyright (C) 2017 Hanan Ouhader and Malika El Kyal. This is an open access article distributed under the Creative Commons Attribution License, which permits unrestricted use, distribution, and reproduction in any medium, provided the original work is properly cited.

\begin{abstract}
This article investigates the potential economic, environmental, and social effects of combining depot location and vehicle routing decisions in urban road freight transportation under horizontal collaboration. We consider a city in which several suppliers decide to joint deliveries to their customers and goods are delivered via intermediate depots. We study a transportation optimization problem from the perspective of sustainability development. This quantitative approach is based on three-objective mathematical model for strategic, tactical, and operational decision-making as a two-echelon location routing problem (2E-LRP). The objectives are to minimize cost and $\mathrm{CO} 2$ emissions of the transportation and maximize the created job opportunities. The model was solved with the $\varepsilon$-constraint method using extended known instances reflecting the real distribution in urban area to evaluate several goods' delivery strategies. The obtained results by comparing collaborative and noncollaborative scenarios show that collaboration leads to a reduction in $\mathrm{CO} 2$ emissions, transportation cost, used vehicles, and travelled distances in addition to the improvement of the vehicles load rate but collaboration affects negatively social impact. To evaluate the effect of the method used to allocate the total gains to the different partners, we suggest to decision makers a comparison between well-known allocation methods.
\end{abstract}

\section{Introduction}

The European commission [1] stated that road transport faces considerable challenges: to ensure mobility on ever more congested road networks, to reduce emissions of pollutants from road transport to preserve the environment and decrease fossil fuel use to improve the fuel security. To address these challenges, governments and firms have to conduct practical initiatives and transform transport policy so as to offer sustainable logistics operations. Collaboration is gaining traction as one of the key policies to improve efficiency and sustainability of road freight transport [2-4].

Supply chain collaboration is defined as "two or more autonomous partners working jointly to plan and execute a supply chain to achieve common goals through a predetermined negotiation based on rules and structures to govern their mutual relationship" [5]. Logistics collaboration was studied in two main areas: vertical and horizontal collaboration. The vertical collaboration occurs between members of the same supply chain (industrial and distributor) while the horizontal collaboration occurs between companies (may be competitors or not) that can provide goods or complementary services [6]. Vertical cooperation has already led to an abundant literature. Nevertheless, less attention has been given to research on horizontal logistics collaboration [7-10].

From the operations management's point of view and as stated in review articles by Amer and Eltawil $[8,11]$ and Danloup et al. [12], existing quantitative models developed in literature for establishing horizontal collaboration in freight transportation was mainly focused on economic approach and the integration of sustainability concerns is accordingly in his infancy. On one hand, the majority of papers on the subject were interested in collaboration between carriers as opposed to that between shippers and on the other hand based on the vehicle routing problem by proposing models only for the operational level of the supply chain and assuming that strategic facility location decisions have been 
met in a prior step and cannot be modified. Additionally, collaborative strategies in urban freight transport remains less explored in the academic literature and most of studies have focused on interurban transport problem [13]. Also, Montoya-Torres et al. [14] put the emphasis on the need to establish models allowing preliminary analysis (before the implementation of collaboration) of the impacts and the benefits that can be achieved under collaborative systems for goods transportation in urban area.

In their study about the sustainability optimization of enterprise logistics network, Zhu and $\mathrm{Hu}$ [15] stated that the integration of society dimension with other two dimensions is not as mature as the integration study of environment dimension with economic dimension. Focusing on sustainability in collaborative supply chain, Chen et al. [16] revealed that research about horizontal collaboration for the purpose of sustainability had received little attention. Evidence regarding the focus of existent research works indicates that the integration of all three dimensions of sustainability has not been taken into account in a single model with multiple objectives for the horizontal collaborative supply chain.

This finding sheds light on the need, for horizontal collaboration between shippers in urban freight transport, of more quantitative models for aiding decisions at strategic, tactical, and operational levels of the supply chain by a preliminary simulation of the impacts of collaboration. These models should integrate all three dimensions of sustainability in a single model with multiple objectives. This requirement is expressed in the concept of the Triple Bottom Line (3BL) in which the social, environmental, and economic goals have to be achieved simultaneously [17].

We are interested in the case of horizontal cooperation between several suppliers (shippers) who decide to joint deliveries to their customers located in urban area. We assume that authorities prohibit large vehicle entry to congested areas with the aim of reducing the GHG emissions of freight distribution, congestion, and accidents. Goods are delivered to customers via intermediate depots (e.g., Urban Consolidation Center (UCC)) rather than direct shipments. Large trucks are used to transport directly goods to intermediate depots where consolidation takes place. After that, products are transferred to customers using small vehicles [18]. The truck service is subcontracting to a private transportation company. Our goal is to minimize the transportation cost and the amount of $\mathrm{CO} 2$ emissions of upstream and downstream transportation in a two-echelon distribution system and maximize the number of created job opportunities. The main decisions involved in this problem are as follows: (1) Which depots/satellites out of a finite set of potential ones should be used? (2) How to assign each customer to one open depot? (3) How to determine routes to perform distribution?

The design of collaborative distribution networks belongs to the domain of supply chain network design. At the transport level, we look for locating a number of hubs among all candidates $N$ and then assigning nonhub nodes to located hubs. This is a facility location problem (FLP). The principle aim is to visit a number of customers at minimum cost and $\mathrm{CO} 2$ emissions and create maximum job opportunities. Thus the consideration of future tours to solve a location problem is necessary. The issue has become a location routing problem, (LRP) which involves three levels of decision: strategic level (the location of facilities such as factories, warehouses, storage, hubs, cross-docks, etc.) besides tactical and operational levels (development of vehicle routing, assignment of customers, etc.). Several researches as $[19,20]$ have shown that this combination provides significant gains on total costs compared with separate decisions. In problem described above, the goods flow passes through intermediate points to carry out breaks loads and the goods are unloaded and loaded in another vehicle. This is a two-echelon distribution system. Thus, this problem can be modeled as an extension of the twoechelon location routing problem (2E-LRP).

The current work does not aim to improve the state of the art of the 2E-LRP or the multiobjective resolution methods; instead the goal of this research is to quantify the impact of including simultaneous routing and facilities location decisions in the designing of the collaborative supply chain with several goods delivery strategies under the Triple Bottom Line approach. We propose a preliminary decision support tool for evaluating the economic, environmental, and social impact of collaborative freight delivery in urban areas before those companies agree to participate in a horizontal cooperation scheme. This quantitative analysis is based on a mathematical model as mixed integer linear problem with three objective functions aiming to minimize cost transportation and $\mathrm{CO} 2$ emissions and to maximize created job opportunities. We compare both collaborative and noncollaborative scenarios by the adaptation of known instances of the 2E-LRP reflecting real distribution urban area. Wellknown allocation methods are compared to evaluate the effect of chosen method in allocated gains.

The rest of this paper is organized as follows: The second section introduces the concept of horizontal collaboration, location routing problem, sustainability, multiobjective approach, and allocation methods. The third section describes the problem under study and our analytical approach. The fourth section discusses the results, whereas the last section deals with our conclusions for the sake of providing a new perspective.

\section{Related Works}

2.1. Horizontal Collaboration in Freight Transport between Shippers. The European commission [21] defined the horizontal collaboration as "an agreement is entered into between actual or potential competitors (...) it also cover horizontal co-operation agreements between non-competitors, e.g., between two companies active in the same product markets but active in different geographic markets without being potential competitors. Horizontal co-operation agreements can lead to substantial economic benefits, in particular if they combine complementary activities, skills or assets. Horizontal cooperation can be a means to share risk, save costs, increase investments, pool know-how, enhance product quality and variety, and launch innovation faster."

There are several ways for horizontal cooperation: carriers can collaborate with each other and shippers can collaborate 
among themselves [22]. Few papers have discussed horizontal cooperation among shippers [12]. From the recent academic literature, Pérez-Bernabeu et al. [22] adapted a set of wellknown benchmarks for the multidepot vehicle routing problem (MDVRP) to illustrate an example of horizontal cooperation between shippers owning the vehicle fleet and quantified routing costs savings both in terms of distance-based costs and in terms of environmental costs due to greenhouse gas emissions. Juan et al. [23] studied the same example as [22] but discussed backhaul in horizontal collaboration to evaluate the relevance of this way in saving routing and environmental costs. Vanovermeire and Sörensen [24] have investigated a cost allocation method from the field of game theory for gain sharing in horizontal collaborative supply chains. Guajardo et al. [25] have studied the cost allocation and coalition structure problems in a real-world case on forest transportation by incorporating the blocking power as a criterion in a cost sharing rule for the horizontal collaboration. Danloup et al. [26] have analyzed the potential for improving sustainability performance in collaborative distribution by measuring the potential improvements regarding the reduced total number of running by delivery trucks and also regarding the reduced amount of $\mathrm{CO} 2$ emissions. Defryn et al. [27] consider a selective vehicle routing problem to clarify the relationship between partners' behavior, routing solution, and cost allocation in horizontal logistic coalition. MontoyaTorres et al. [14] used the multidepot vehicle routing problem (MDVRP) for horizontal collaborative delivery between firms and a variant of the location-allocation problem to design the transport infrastructure. Defryn et al. [28] show the impact of a certain allocation method when applied in the broader context of horizontal cooperation in French food case. Tang et al. [29] modeled as a facility location problem (FLP) a case aiming at determining optimal locations of regional distribution centers in a collaborative distribution network for horticultural products in France. Soysal et al. [10] were interested in analyzing the benefits of horizontal collaboration related to perishability, energy use (CO2 emissions) from transportation operations, and logistics costs in the Inventory Routing Problem (IRP) with multiple suppliers. Kuyzu [30] adopted the partner constrained lane covering problem (PCLCP) by providing an extended formulation which addresses the limits on the number of collaborative partners and developed a column generation approach for its solution. The aim was to prove the efficiency of this heuristic. Park et al. [31] formulated a courier, express, and parcel (CEP) delivery in last-mile networks to estimate the effects of logistics collaboration for apartment complexes. A capacitated vehicle routing problem CVRP was employed to modelize the problem. Newly, Muñoz-Villamizar et al. [32] studied the implementation of an electric fleet of vehicles in collaborative urban distribution of goods, in order to reduce environmental impacts while maintaining a level of service. They proposed an approach using mathematical modeling with multiple objectives, for tactical and operational decisionmaking to explore the relationship between the delivery cost and environmental impact. In our previous works [33, 34], we quantified the economic and the environmental benefits of horizontal collaboration using single objective 2E-LRP model with a posteriori evaluation of the impact of collaboration in $\mathrm{CO} 2$ emissions based in travelled distances.

This brief review of recent contributions in the horizontal collaboration in freight transport between shippers confirms the findings of introductory part. Most of the works presented a postanalysis of the collaboration impact and results are obtained after implementation in practice. Focusing on the modeling aspect of these works, the majority of papers are based on vehicle routing problem and its variants. Also, the work of Muñoz-Villamizar et al. [32] was the only study found evaluating the impact of horizontal collaborative urban transport network considering multiobjective approach.

To the best of authors' knowledge, the two-echelon location routing problem has never been used before to evaluate simultaneously the effect of routing and facilities location decisions in the collaborative freight transport under the Triple Bottom Line approach.

The main contribution of this work is to provide a preliminary decision support tool for simultaneous evaluating of the economic, environmental, and social benefits of horizontal collaborative freight delivery in urban areas. The problem is modeled as a multisources two-echelon location routing problem (2E-LRP) under multiobjective approach. In particular, we optimize the total transportation, the total transportation emission, and the created job opportunities. This quantitative analysis is based on the adaptation of a well-known set of benchmarks for the 2E-LRP. To allocate costs, emissions, and created job to different partner of the coalition, we propose to decision makers a comparison between the simple proportional allocation rules and the Shapley value method belonging to the field of cooperative game theory.

2.2. Two-Echelon Location Routing Problem. As defined by Cuda et al. [35], the two-echelon location routing problem (2E-LRP) involves both strategic (typically the location of facilities) and tactical (typically the routing of freight and the allocation of customers to the intermediate facilities) planning decisions. Goods are available at different sources and have to be delivered to the respective destinations moving mandatorily through intermediate facilities called depots or satellites. An opening cost is associated with each source and each satellite. Sources and depots, to be opened, have to be selected from a set of possible sources (depots) location.

The (2E-LRP) is relatively associated with other variants of the multilevel transportation problems. The two-echelon facility location problem (2E-FLP) represents a special case of 2E-LRP when customers are served by dedicated truck (no tours) and the two-echelon vehicle routing problem (2EVRP) represents a special case of 2E-LRP when the depots are already located [36].

For the most recent contributions the interested reader is addressed to the surveys by Drexl and Schneider [37] and Prodhon and Prins [38] who published two exhaustive literature reviews of LRP and these variants. In particular, Cuda et al. [35] provide an overview of 2E-LRP. These recent reviews can be considered as complementary and provide a wide and detailed review of all the last advances (exact and heuristic approaches) and applications of LRP [39]. 
From these reviews we can conclude that the majority of existing researches on the LRP have focused on economic approach, single echelon, and single source at a fixed location. Multiechelons (like 2E-LRP) and multiobjectives LRP begins to attract the interest of researchers in recent years.

2.3. Measurement of Sustainability Dimensions. In the past, this concept was more environmentally oriented. Nowadays, sustainability is considered to be supported by three main pillars: economic, environmental, and also social sustainability [41]. Seuring and Müller [42] defined sustainable supply chain management as "the management of material, information and capital flows as well as cooperation among companies along the supply chain while taking goals from all three dimensions of sustainable development, i.e., economic, environmental and social, into account which are derived from customer and stakeholder requirements."

2.3.1. Economic Dimension. As mentioned in [15], the general measurement of the economic factor is based on the calculation of total network cost or net profit. Total network cost usually includes facility establishment cost, transportation cost, inventory cost, and production cost. In our work we are interested in transportation cost and facilities opening costs.

2.3.2. Environmental Dimension. The measurement of environment factor is usually based on $\mathrm{CO} 2$ emissions. For quantifying CO2 emissions, Velázquez-Martínez et al. [43] stated that emissions cannot be measured but need to be estimated. The estimation of fuel consumption and $\mathrm{CO} 2$ emission transportation requires complex calculations, which can only represent an approximation because of the difficulty of quantifying some variables as driving style, weather conditions, or congestion [44]. In their review of recent research on green road freight transportation, Demir et al. [45] presented the factors affecting fuel consumption. They concluded that the fields of green road freight transportation have focused on a limited number of factors, mainly vehicle load and speed. In dependence of a bunch of parameters, a variety of methods for estimating fuel consumption and emission of road transportation exist [46]. The decision on which model to adopt depends mainly on data availability [45]. For the most recent contributions the interested reader is addressed to the book chapter of Bektas et al. [47].

Due to the complexity of the estimation of CO2 emissions, our calculation is simplified and based on European studies as [9, 48-50]. In this study, CO2 emissions depend on the weight carried by the vehicle, on the capacity of the vehicle that is used, on the distance travelled, and on the average speed of the vehicle. The calculation formula of $\mathrm{CO} 2$ emissions with the variable of load is

$$
\begin{aligned}
& \varepsilon\left(d_{i j}, c_{k}, x_{i j}^{k}\right)=\sum_{k} \sum_{i} \sum_{j} d_{i j} \\
& \quad *\left[\left(E_{(\text {full })}-E_{(\text {empty) }}\right) * \frac{x_{i j}^{k}}{c_{k}}+E_{(\text {empty) }} *\left\lceil\frac{x_{i j}^{k}}{c_{k}}\right\rceil\right] .
\end{aligned}
$$

$\varepsilon(d, c, x)$ is the $\mathrm{CO} 2$ emissions from a vehicle in $\mathrm{g} / \mathrm{km}$. The variable $x_{i j}^{k}$ is the flows on $\operatorname{arcs}(i, j)$ loaded on vehicle of type $k$ in unit. $E_{(\text {full })}$ is the CO2 emissions of a fully loaded (by weight) vehicle. $E_{\text {(empty) }}$ is the $\mathrm{CO} 2$ emissions of an empty vehicle, $c_{k}$ is the capacity of a type $k$ vehicle, and $d_{i j}$ is distance on the arc $i j$. The term $\left\lceil x_{i j}^{k} / c_{k}\right\rceil$ represents the nearest larger integer to $x_{i j}^{k} / c_{k}$.

For the calculation of the values of $E_{(\text {full) }}$ and $E_{\text {(empty) }}$, we used data adapted by Moutaoukil et al. $[9,49]$ and provided by Hickman 1999 [48]. These values are linked to the average speed of the vehicle used which depends on the type of path in urban, regional, or national routes [51].

2.3.3. Social Dimension. In practice it is difficult to measure all social aspects in a single decision-making problem [17]. Due to the difficulty in measuring such impacts, there is a strong deficit in the amount of published literature on social impact assessment [41]. The Guidance on Social Responsibility ISO-26000 serves as guidelines for social performance measurement. ISO 26000 classifies social issue into seven aspects: labor practice, customer issues, organization governance, human rights, fair operating, environment, and community development. The number of jobs created is the most used metric to evaluate social impact in supply chain. Created job opportunities are divided into two categories [52]: fixed jobs (like managers) which do not depend on the capacity of a facility like managerial positions and variable jobs like workers that vary by the used capacity of facilities. In this paper, we are focusing on created variable jobs opportunities which depend on the capacity of satellites.

2.4. Multiobjective Approach. We pretend to provide a solution of compromise between economic, environmental, and social impacts. For that, this work also comprehends a multiobjective approach. The multiobjective problem has no single optimal solution. Bouchery et al. [53] explained that the multiobjective optimization looks at identifying particular solutions called efficient or Pareto optimal such that, when attempting to improve an objective further, other objectives suffer as a result. It is well known that the weighted sum method is not capable of finding nonsupported points. To obtain the tradeoff solutions among all dimensions of sustainability, $\varepsilon$-constraint method is used to solve the proposed model. As explained by $\mathrm{Zhu}$ and $\mathrm{Hu}$ [15], (2) describes the multiobjective model. In the equation, $x$ is the vector of decision variables, and $X$ represents the feasible region. The economical objective, environmental objective, and social objective are represented by $f 1(x), f 2(x)$, and $f 3(x)$, respectively:

$$
\min (f 1(x), f 2(x)) \wedge \max f 3(x), \quad x \in X
$$

In the $\varepsilon$-constraint method, the objective with higher priority is considered as the objective function while others are written as constraints by using constraint vector $\varepsilon$. Here, the economical objective is chosen to be optimized. Then, the 
model is transformed to (3), where $k=0, \ldots, n, \Delta \varepsilon i=$ $f \max (x)-f \min (x) ; i=2,3$, and $r i=f \max (x)-$ $f \min (x) / n$ denotes the range of objectives

$$
\begin{gathered}
\min f 1(x) \\
f 2(x)<f 2 \min (x)+k \Delta \varepsilon 2 \\
f 3(x)<f 3 \min (x)+k \Delta \varepsilon 3 \\
\quad x \in X .
\end{gathered}
$$

2.5. Gains Allocation Mechanism. In horizontal collaboration, the partners are generally not interested in the profits generated by the entire alliance but in the impact of the cooperation on their own profit and loss (P\&L) [54]. Thereby, according to Cruijssen and BV [55], one of the main challenges in horizontal collaboration is to ensure a fair allocation of synergy estimated to all partners. Many cost allocation mechanisms were proposed in the literature. Recently, Guajardo and Rönnqvist [56] provided a survey on cost allocation methods found in the literature on collaborative transportation and also described the theoretical basis for the main methods as well as the cases where they are used. Several of these methods come from previous work on cooperative game theory. Defryn et al. [28] stated that no single cost allocation method works best in all situations and many researchers acknowledge the need for a casespecific approach. These methods are primarily formulated to distribute economic gains among members in collaborative scenarios but they are in principle useful for allocating other metrics [57].

To help the coalition to choose the appropriate allocation mechanism we propose to decision makers a comparison between the simple proportional rules and the Shapley value method belonging to the field of cooperative game theory.

2.5.1. The Shapley Value Method. The Shapley value method [58] takes into account the partners' contribution to all possible (sub)coalitions. As explained by Vanovermeire et al. [54], for each player, this value is calculated as the weighted average of the marginal contributions of this player to any possible coalition that can be formed given the game at hand. This implies that the cost effect that each player generates when he is added to the coalition as well as the different subcoalitions is used to determine the allocated profit. The cost allocated to partner $p$ can be calculated by using (2). Given a player $i$ and a coalition $N$, which consists of subcoalitions $S \subseteq N$, where each generates a cost $c(S)$, the Shapley value is

$$
C_{i}^{\text {Shapley }}=\sum_{S \subseteq N \backslash i} \frac{|S| !(n-|S|-1) !}{n !} *(c(S \cup i)-c(S)) \text {. }
$$

2.5.2. Proportional Methods. Proportional methods, as defined by Guajardo and Rönnqvist [56], are those where each player $j$ is assigned a share $\alpha j$ of the total cost $C(N)$; that is, $x j=\alpha j * C(N) \forall j \in N$, where $\sum \alpha j=1$. The share values $\alpha j$ can be defined according to different criteria. The simplest one is the "egalitarian" method which assigns equal cost shares to all the players; that is, $x j=C(N) / n \forall j \in$ $N$. Some other frequent criteria to define the weights $\alpha j$ are the demand quantities and the stand-alone costs. From these proportional methods we choose the linear rule method which uses the stand-alone cost/emissions/jobs to define the relative importance of each partner and the volume-based allocation method which allocates the cost/emissions/jobs of the coalition based on each partner's shipped volume.

\section{Problem Formulation}

3.1. Problem Description. There is no predefined scheme for the horizontal collaboration in freight transportation. It takes many forms and several configurations which can be probable scenarios to test the collaborative approach. In our study, we consider the case of companies wishing to pool their deliveries to their customers (which may be common). From existing distribution platforms, we look for locating where the charge's breaks will operate. Transportation between partners and localized platforms is direct. Delivery to different clients is done in multidrop. The truck service is subcontracted to a private transportation company. We want to optimize flows of upstream and downstream transportation by minimizing costs and carbon emissions and maximizing created job opportunities in a two-level network (suppliers-platforms, platforms-clients).

3.2. Model Description. Our problem is defined on an undirected, weighted, and complete graph. The nodes are partitioned into three subsets: $K=\{1,2, \ldots, F\} F$ factories, $J=\{1,2, \ldots, W\} W$ satellite/possible platform, and $I=$ $\{W+1, W+2, \ldots, W+S\} S$ clients. Each $j \in J$ satellite has a capacity $W \operatorname{cap}(j)$ and an opening cost $H j$. Each satellite works as a cross-dock, meaning that when products arrive at the cross-dock, they are unloaded at the receiving dock before being split and consolidated with other products according to customer's orders [59]. So we considered a transshipment cost $L j$ proportional to the quantity loaded or unloaded in the cross-dock. Satellites do not perform any other activity. Each customer $i \in I$ has a demand $q(i p)$ for each product $p \in P$ such as $P=\{1,2, \ldots, F\} F$ product (each plant has its own product). A homogeneous fleet of trucks with the same capacity Tcap and fixed cost FCT (primary or firstlevel vehicles) serves the satellites. A homogeneous fleet of smaller vehicles (secondary or second-level vehicles) with the same capacity $V$ cap and fixed cost FCV is shared by the open satellites to supply customers.

The following assumptions are considered in order to model the two-echelon location routing problem for horizontal collaboration in distribution.

(i) We analyze an ideal scenario for collaboration in which both companies are encouraged to share their customers to optimize their individual costs, carbon emissions, and created job opportunities. 
(ii) The density of the current logistics site is important and optimized. Their location allows finding the solution among current locations.

(iii) The factories and the total capacity of satellites can satisfy the whole demand.

(iv) All products are compatible.

(v) Each client demand must be served by a single tour.

(vi) Each client is associated with only one satellite.

(vii) Each tour in second level should start and end in the same satellite.

(viii) Connections between the satellites are not allowed.

(ix) A factory can supply several satellites.

The sets, parameters, and decision variables used in this research are defined as in the Notations.

3.2.1. Objectives Functions. The goal is to identify the satellites to open (how much and on which nodes of the graph) and what tours to build (how many customers associate with each satellite and composition of each customers' chain) to respect the assumptions listed above and to minimize the total cost and $\mathrm{CO} 2$ emissions of transportation and maximize created job opportunities. We formulate the problem as a Mixed Integer Linear Programming (MILP) with binary and continuous variables.

(1) Minimization of Economic Cost. Objective function (5) corresponds to the minimization of the total of transportation cost. It includes the cost of satellites opening, the handling cost in the satellites, the fixed costs of trucks and vehicles, and the traversal costs of the arcs in the two distribution levels:

$$
\begin{aligned}
\min \mathrm{ECON}= & \sum_{j} H_{j} * y_{j}+\sum_{k} \sum_{j} L_{j} * f_{(k j)} \\
& +\sum_{k} \sum_{j} \mathrm{FCT} * N_{(k j)}+\sum_{j} \mathrm{FCV} * R_{j} \\
& +\sum_{k} \sum_{j} N_{(k j)} * C_{(k j)}+\sum_{j} \sum_{i} C 1_{j i} * x 1_{j i} \\
& +\sum_{j} \sum_{i} C 2_{(i j)} * x 2_{i j} \\
& +\sum_{i} \sum_{l} \sum_{j} C 3_{i l} * x 3_{i h j} .
\end{aligned}
$$

(2) Minimization of $\mathrm{CO} 2$ Emissions. Objective function (6) corresponds to the minimization of environmental impacts. It is obtained by adapting function (1) defined in Section 2. In our formulation, we take into account the emissions of empty returns of vehicles in the routing stage. The first term of function (6) represents the emissions induced by the trucks in the first echelon, and the others represent the emissions induced by the vehicles in the second echelon:

$$
\begin{aligned}
& \min \operatorname{ENVR}=\sum_{k} \sum_{j} d_{k j} *\left[\left[\left(E_{\left(T_{\text {full }}\right)}-E_{\left(T_{\text {empty }}\right)}\right) * \frac{f_{(k j)}}{T \text { cap }}\right]\right. \\
& \left.+\left[E_{\left(T_{\text {empty }}\right)} * N_{(k j)}\right]\right]+\sum_{p} \sum_{j} \sum_{i} d_{j i} \\
& +\left[\left[\left(E_{\left(V_{\text {full }}\right)}-E_{\left(V_{\text {empty }}\right)}\right) * \frac{U_{(p j i)}}{V \text { cap }}\right]+\left[E_{\left(V_{\text {empty }}\right)} * x 1_{j i}\right]\right] \\
& +\sum_{p} \sum_{i} \sum_{h} \sum_{j} d_{i l j} \\
& \quad *\left[\left[\left(E_{\left(V_{\text {full }}\right)}-E_{\left(V_{\text {empty }}\right)}\right) * \frac{U_{(p i h j)}}{V \text { cap }}\right]+\left[E_{\left(V_{\text {empty }}\right)} * x 3_{i h j}\right]\right] \\
& +\sum_{i} \sum_{j} d_{i j} *\left[E_{\left(V_{\text {empty }}\right)} * x 2_{i j}\right] .
\end{aligned}
$$

(3) Maximization of Social Impact. Objective function (7) corresponds to the maximization of social impact to quantify the created job opportunities. We are interested in variable jobs (workers) that vary by the capacity of facilities:

$$
\max \mathrm{SOC}=\sum_{k} \sum_{j} \mathrm{OV}_{j} * \frac{f_{k j}}{W \mathrm{cap}_{j}} .
$$

\subsubsection{Constraints}

$$
\begin{aligned}
& \sum_{j} f_{k j} \leq F \operatorname{cap}_{(k)} \quad \forall k \\
& N_{(k j)} \geq \frac{f_{k j}}{T \text { cap }} \quad \forall k ; j \\
& \sum_{k} f_{k j} \leq W \operatorname{cap}_{(j)} * y_{j} \quad \forall j \\
& \sum_{k} f_{k j}=\sum_{i} \sum_{p} D_{(i p)} * w_{i j} \quad \forall j \\
& \sum_{k} w_{i j}=1 \quad \forall i \\
& \sum_{j} f_{k j}=\sum_{i} q_{(i p)} \quad \forall p ; k \\
& R_{(j)} \geq \frac{\sum_{i} \sum_{p} q_{(i p)} * w_{i j}}{V \mathrm{CAP}} \quad \forall j \\
& \sum_{i} x 1_{j i}=\sum_{i} x 2_{i j} \quad \forall j \\
& x 1_{j i}+\sum_{h} x 3_{h i j}=x 2_{i j}+\sum_{l} x 3_{i l j} \quad \forall i ; j \\
& \sum_{i \in I \cup\{j\}} x 3_{i h j}=w_{l j} \quad \forall l ; j
\end{aligned}
$$




$$
\begin{aligned}
& \sum_{\substack{h \in I \cup\{j\} \\
l \neq i}} x 3_{i h j}=w_{i j} \quad \forall i ; j \\
& \sum_{j} x 1_{j i}+\sum_{j} \sum_{h} x 3_{h i j}=1 \quad \forall i \\
& \left(\sum_{j} U_{p j i}+\sum_{j} \sum_{i \neq h} U_{p h i j}\right)-\left(\sum_{j} \sum_{i \neq l} U_{p i l j}\right) \\
& =\sum_{j} \sum_{p} q_{(i p)} * w_{i j} \quad \forall i ; p \\
& \sum_{p} q_{(i p)} * x 1_{j i}+\sum_{h} \sum_{p} x 3_{i h j} * q_{(h p)} \leq U_{p j i} \\
& \leq V \text { cap } * x 1_{j i} \quad \forall j ; i \\
& \sum_{p} q_{(h p)} * x 3_{i h j} \leq U_{p i h j}<V \text { cap } * x 3_{i h j} \quad \forall j ; i ; h \\
& \sum_{i} d_{j i} * x 1_{j i}+\sum_{i} \sum_{h} x 3_{i h j} * d_{i l j}+\sum_{i} d_{i j} * x 1_{i j} \\
& \leq T * V \quad \forall j \\
& x 1_{j i}, x 2_{i j}, x 3_{i l j}, w_{i j}, y_{j} \in\{0,1\} \quad \forall i ; l ; j \\
& U_{p i h j} \geq 0 ; U_{p j i} \geq 0 ; f_{k j} \geq 0 \quad \forall i ; h ; j ; k ; p \\
& R_{(j)}, N_{(k j)} \in Z^{+} \quad \forall j ; k .
\end{aligned}
$$

Constraints (8) guarantee not exceeding factory capacity. Constraints (9) connect the amount of goods sent from each plant to each satellite with truck capacity. Constraints (10) require that the sum of the products sent to each satellite must not exceed its capacity, and if $y_{j}=0$, no product is sent to the satellite $j$. Constraints (11) specify that the quantity of products sent to each satellite must be the same as the sum of the demands of all customers assigned to this satellite. Constraints (12) ensure that each client is assigned to a single satellite. Constraints (13) ensure that the quantity of product produced by each plant is the same as the sum of customers' demands of this product. Constraints (14) calculate the number of 2nd-level vehicles required to meet demand. Constraints (15) guarantee that each route must start and end at the same depot. Constraints (16), (17), and (18) define the sequencing of the entire route for all clients, establishing that each customer must be visited immediately after satellite or after another customer, and a customer or satellite must be visited immediately after. These constraints allow route, only, between the clients assigned to the same satellite. Constraints (19) are typical node balance constraint guaranteeing that each customer is visited only once. Constraints (20) are used to model the flow on each arc in the routing stage by computing the vehicle's payload along the tour so as also to eliminate subtours that do not include the satellites, since the load on each vehicle is monotonically decreasing as customers are visited [60]. Constraints (21) and (22) ensure that the maximum vehicle capacity is not violated and also forces amounts $U_{p i h j}$ and $U_{p j i}$ to be zero if, respectively,

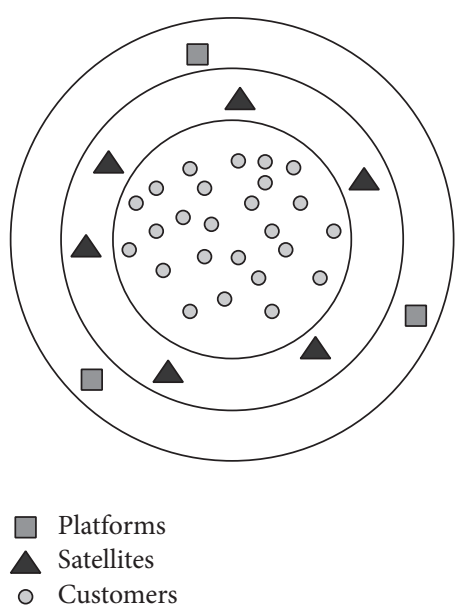

Figure 1: Satellite distribution in the I1 instances (from [40]).

$\operatorname{arcs}(j ; i)$ and $(i ; h)$ are not travelled. Constraints (23) establish the maximum time length of routes. All variables are defined in constraints (24)-(26).

\section{Computational Evaluation}

4.1. Instances Description. In this section, the proposed model, presented in Section 3, is validated and tested for small, medium, and large size data instances. The model is implemented by using commercial solver (MATLAB 2014) and tested on a $2.67 \mathrm{GHz}$ Core i5 with $4 \mathrm{~GB}$ RAM under Windows 7 environment.

To the best of our knowledge, there are no available benchmark instances in literature to test our model. For this reason, we are inspired by standard instances existing in the literature. We have chosen Sterle's instances [61] regenerated by Contardo et al. [62] according to the specifications explained in [40] with the scope of reproducing a schematic representation of a multilevel urban area (instances are available in http://claudio.contardo.org/instances/).

Three sets of instances (I1, I2, and I3) were regenerated by [62]. They differ in the location of the satellites and platforms. The number of customers in these instances ranges from 8 to 200 , the number of satellites ranges from 3 to 20 , and the number of platforms ranges from 2 to 5 .

The performance of the developed model in terms of computation time is addressed using 6 data sets selected from Sterle's instance I1 (Figure 1) and ranging from small-scale instances to large ones. These sets have the following features: number of customers $\{15,25,40,75,100,200\}$, number of factories $\{2,3,4,5\}$, number of satellites $\{3,4,5,8,10,20\}$, demands in the range $[1,100]$, capacities of satellites in the range [550;950], opening costs in the range [45;75], and transshipment costs in the range [0.02; 0.07]; the costs Cij are the Euclidean distances and they are doubled in the first level.

In this study, emissions are limited to carbon dioxide (CO2) caused by transportation activities. These emissions are estimated based on the MEET model, which is developed by Hickman [48] and widely used in the literature. We refer to $[9,49]$ to determine $E_{(\text {empty) }}$ and $E_{(\text {full })}$ for trucks 
TABLE 1: Truck and vehicle characteristics.

\begin{tabular}{lcc}
\hline & $\begin{array}{c}\text { Trucks } \\
\text { (regional routes) }\end{array}$ & $\begin{array}{c}\text { Vehicle } \\
\text { (urban routes) }\end{array}$ \\
\hline Capacity & 800 & 200 \\
Fixed cost & 100 & 50 \\
Average speed $(\mathrm{km} / \mathrm{h})$ & 45 & 20 \\
Total authorized weight (ton) & $7.5-16$ & $<1.5$ \\
$E_{\text {(empty) }}(\mathrm{g} / \mathrm{CO} 2)$ & 532.6 & 59 \\
$E_{\text {(full) }}(\mathrm{g} / \mathrm{CO} 2)$ & 479.82 & 58,6 \\
\hline
\end{tabular}

and vehicles. We used fleets of homogeneous vehicles and trucks. Their characteristics were summarized in Table 1 . The maximum route time $T$ for the urban route was fixed at $8 \mathrm{~h}$. This means that the routes cannot exceed this length. In order to replicate the experiments, full origin-destination matrixes and demand sets are available upon request to the corresponding authors of this paper.

4.2. Optimization Approach. In the mathematical models presented above, costs, CO2 emissions, and created job opportunities are considered as the objective functions to optimize. In order to provide a useful tool for decision makers addressing such issues, we present two decision-making scenarios: (i) noncollaborative scenario, NCS, in which horizontal collaboration does not exist between the suppliers; (ii) collaborative scenario CS in which horizontal collaboration exists between the suppliers. The 2E-LRP models can be implemented to analyze both scenarios using the parameters described in Notations.

In the scenario NCS, each manufacturer must define its own distribution scheme and solve the models separately. This scheme is modeled as a 2E-LRP (mathematical models in Section 3) with a single source $(F=1)$. In the scenario CS, the industrials share resources and information to develop common distribution patterns. This situation is modeled as a multisource LRP-2E $(F=\{2,3,4,5\})$.

4.2.1. Monoobjective Approach. First, we opt for a single objective approach to discuss the potential effects of horizontal collaboration in the supply chain studied in this paper.

Three cases are analyzed: (i) cost minimizing case (C_min) in which the model is solved considering only the objective function that minimizes (function (5)); (ii) emissions minimizing case (Em_min) where the model is solved for optimal levels of $\mathrm{CO} 2$ emissions (function (6)); (iii) social impact maximization case (Soc_max) where the model is solved for optimal levels of job opportunities created (function (7)).

The performance of the developed models in terms of computation time (CPU times in seconds) is shown in Table 2 in the case of collaborative scenario (CS).

For small and medium instances the model is able to determine the optimal solution by Matlab solver within one hour (3600 seconds), but for large instances the formulation requires much computation time (more than 9 hours for instance with 20 satellites). As the LRP-2E is an NP-hard problem combining location and routing decisions, specific heuristic and metaheuristics approach must be used in order to tackle the problem on large size instances.

To study the potential effects of horizontal collaboration in the supply chain, the proposed evaluation process consists of a comparison between the performance of the noncollaborative scenario and the collaborative one. Transportation cost, $\mathrm{CO} 2$ emissions, and created job opportunities are considered as the objective functions to optimize. A posteriori evaluation of other metrics can be assessed such as the opened satellites, the customers' allocation, the number of the used vehicles and trucks, vehicles loading rate, and travelled distances. For this reason we zoom in a case of 3 plants (suppliers), 5 satellites, and 40 costumers (set 3 in Table 2).

We assume that suppliers have different sizes in terms of total amount of products sent to the customers which are not common between suppliers. Each factory has its own and unshared customers with other partners (see Table 3).

(1) Noncollaborative Scenario (NCS). Three cases are analyzed to evaluate the actual situation (noncollaboration): cost minimizing case (C_min), emission minimizing case (Em_min), and social impact maximization case (Soc_max). For the three suppliers, in order to compare the three extreme solutions, the results obtained from both cases are presented in Table 4. In addition to cost transportation, the CO2 emissions amount, and the created job opportunities, other parameters can be assessed. Summary results for the three cases are presented in Table 5. The third to last columns show the total of travelled distances in levels by trucks and vehicles, the number of used trucks, number of used vehicles (city freighters), the open satellites and number of assigned customers to these satellites, the average load rate of the tracks, and the average load rate of the vehicles. The row (Total_NCS) presents the global situation of our supply chain in a stand-alone scenario (aggregated contributions of all partners).

For the three suppliers, Figure 2 indicates that lower environmental impact comes with a higher cost and higher social impact corresponds to higher cost.

For supplier F1, a 49,98\% reduction in carbon emissions can be achieved at $22 \%$ increase in the cost of the C_min case. This result can be explained by the reduction of travelled distances due to change in open satellites in Em_min case. These satellites have more expensive opening or transshipment costs, which justifies the increase of transportation cost. In the case of Soc_max a 4,55\% improvement on social impact can be achieved in $81,21 \%$ increase in the cost of the C_min case which leads to the selection of different depots and the transportation distance increases accordingly.

Between the three base cases, the average load rates of truck (TLR) do not change because the same number of trucks and open satellites is considered in both cases. Also, the average load rates of vehicle (VLR) do not change due to the fact that one satellite is open in both cases and all customers are assigned to this satellite, except for supplier F1; VLR increase in Soc_max case as the number of vehicle decreases and the number of customers assigned to satellites changes compared to other cases. Observed trends 
TABLE 2: The performance of the developed model in collaborative scenario.

\begin{tabular}{|c|c|c|c|c|c|c|c|c|c|}
\hline \multirow[b]{2}{*}{ Set } & \multicolumn{3}{|c|}{ Instances } & \multicolumn{3}{|c|}{ Objectives' functions } & \multicolumn{3}{|c|}{ CPU times (second) } \\
\hline & $F$ & $W$ & $S$ & Cost $(€)$ & $\begin{array}{l}\text { Emissions } \\
(\mathrm{gCO} 2)\end{array}$ & $\begin{array}{l}\text { Social impact } \\
\text { (created job) }\end{array}$ & C_min & Em_min & Soc_max \\
\hline 1 & 2 & 3 & 15 & 465 & 3687 & 10 & 6,63 & 7,96 & 3,16 \\
\hline 2 & 3 & 4 & 25 & 1143 & 25803 & 27 & 37,61 & 28,82 & 13,45 \\
\hline 3 & 3 & 5 & 40 & 1726 & 31422 & 38 & 525,26 & 238,25 & 165,66 \\
\hline 4 & 4 & 8 & 75 & 3735 & 73118 & 62 & 3679,59 & 1923,61 & 787,98 \\
\hline 5 & 5 & 10 & 100 & 5846 & 109725 & 91 & 10238,71 & 4525,26 & 2895,79 \\
\hline 6 & 5 & 20 & 200 & 13765 & 375095 & 169 & 32632,00 & 20891,00 & 9675,38 \\
\hline
\end{tabular}
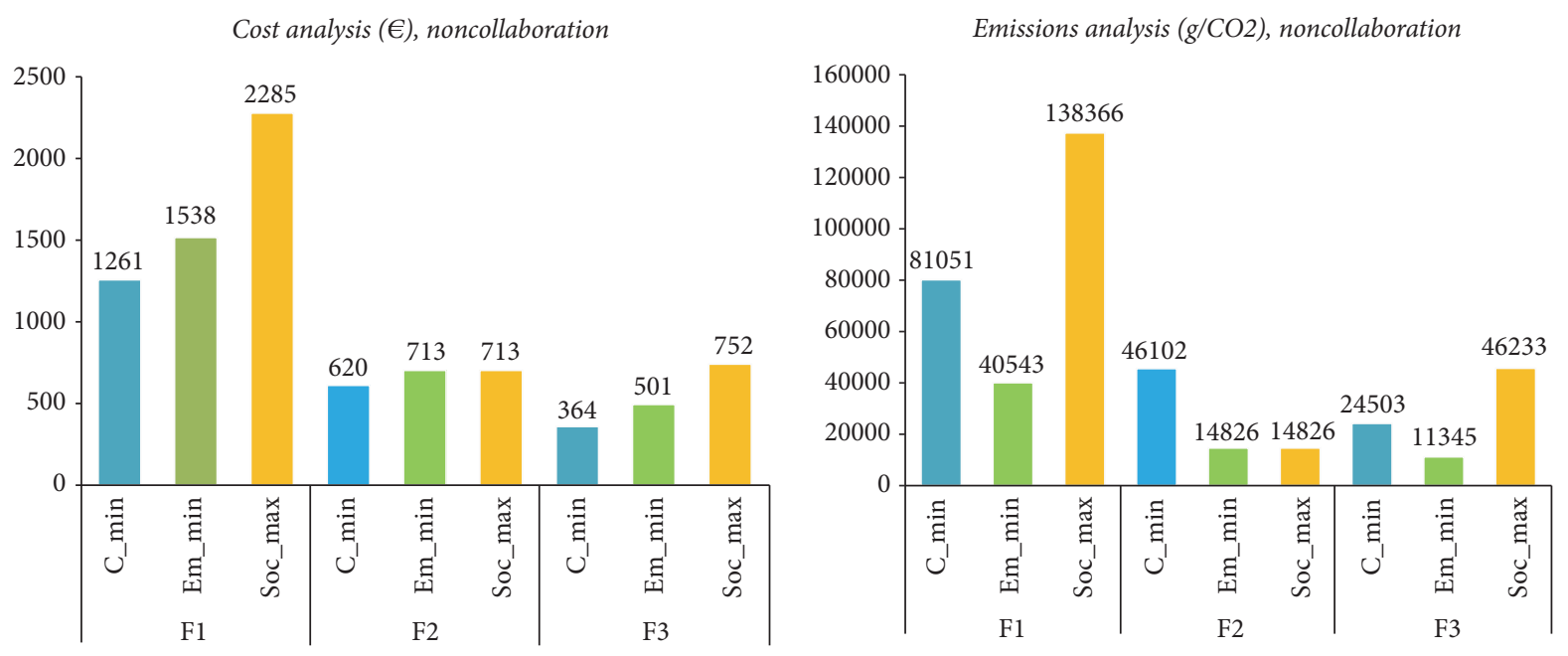

Social metric analysis (number of job opportunities), noncollaboration

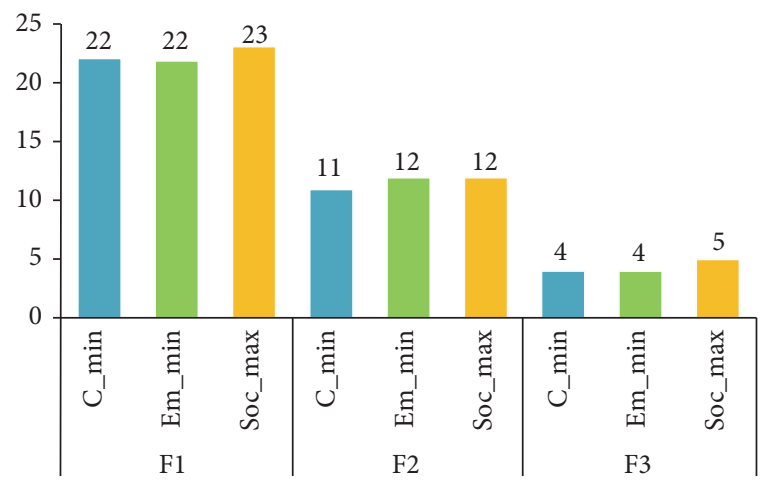

FIGURE 2: Cost, emissions, and social metric analysis of extreme solutions (C_min versus Em_min versus Soc_max) in noncollaborative scenario.

TABLE 3: Suppliers' characteristics.

\begin{tabular}{lccc}
\hline Supplier & Capacity & $\begin{array}{c}\text { Number of } \\
\text { customers }\end{array}$ & $\begin{array}{c}\% \text { of the total shipped } \\
\text { volume of the } \\
\text { coalition }\end{array}$ \\
\hline F1 (big size) & 3000 & 20 & $60 \%$ \\
F2 (medium size) & 1000 & 12 & $29 \%$ \\
F3 (small size) & 500 & 8 & $11 \%$ \\
\hline
\end{tabular}

in the global situation (aggregated values) in noncollaborative scenario (Total_NCS) can be explained in the same way as what has preceded.

(2) Collaborative Scenario (CS). To discuss the potential effects of horizontal collaboration in our supply chain, the cooperative scenario was compared to its noncooperative counterpart. Also, in this section, three cases are analyzed: 
TABLE 4: Comparison between extreme solutions for noncollaborative scenario.

\begin{tabular}{|c|c|c|c|c|c|}
\hline Factory & Case & Cost $(€)$ & $\begin{array}{c}\text { Emissions } \\
(\mathrm{gCO} 2)\end{array}$ & $\begin{array}{c}\text { Job } \\
\text { opportunities }\end{array}$ & Comparison \\
\hline \multirow{3}{*}{$\mathrm{F} 1$} & C_min & 1261 & 81051 & 22 & \multirow{3}{*}{$\begin{array}{l}{ }^{*} \text { Cost increase by } 22 \% \\
\text { Emissions reduced by } 49,98 \% \\
{ }^{* *} \text { Cost increase by } 81,21 \% \text {; social impact improved by } 4,55 \%\end{array}$} \\
\hline & Em_min* & 1538 & 40543 & 22 & \\
\hline & Soc_max ${ }^{* *}$ & 2285 & 138366 & 23 & \\
\hline \multirow{3}{*}{$\mathrm{F} 2$} & C_min & 620 & 46102 & 11 & \multirow{3}{*}{$\begin{array}{l}{ }^{*} \text { Cost increase by } 15 \% \\
\text { Emissions reduced by } 67,84 \% \\
{ }^{* *} \text { Cost increase by } 15 \% \text { Social impact improved by } 9,09 \%\end{array}$} \\
\hline & Em_min* & 713 & 14826 & 12 & \\
\hline & Soc_max ${ }^{* *}$ & 713 & 14826 & 12 & \\
\hline \multirow{3}{*}{ F3 } & C_min & 364 & 24503 & 4 & \multirow{3}{*}{$\begin{array}{l}{ }^{*} \text { Cost increase by } 37,69 \% \\
\text { Emissions reduced by } 53,70 \% \\
{ }^{* *} \text { Cost increase by } 106,5 \% \text {; social impact improved by } 25 \%\end{array}$} \\
\hline & Em $\min ^{*}$ & 501 & 11345 & 4 & \\
\hline & Soc_max** & 752 & $\begin{array}{l}11345 \\
46233\end{array}$ & $\begin{array}{l}4 \\
5\end{array}$ & \\
\hline \multirow{3}{*}{$\begin{array}{l}\text { Total_NCS } \\
=\mathrm{F} 1+\mathrm{F} 2+\mathrm{F} 3\end{array}$} & C_min & 2245 & 151656 & 37 & \multirow{3}{*}{$\begin{array}{l}{ }^{*} \text { Cost increase by } 22,60 \% \\
\text { Emissions reduced by } 56,01 \% \\
{ }^{* *} \text { Cost increase by } 67 \% \\
\text { Social impact improved by } 8,11 \%\end{array}$} \\
\hline & Em_min ${ }^{*}$ & 2752 & 66714 & 38 & \\
\hline & Soc_max ${ }^{* *}$ & 3750 & 199425 & 40 & \\
\hline
\end{tabular}

TABLE 5: Summary results for the base case of noncollaborative scenario.

\begin{tabular}{|c|c|c|c|c|c|c|c|}
\hline Factory & Scenario & $\begin{array}{c}\text { Travelled } \\
\text { distances } \\
(\mathrm{Km}) \\
\end{array}$ & $\begin{array}{l}\text { Trucks' } \\
\text { number }\end{array}$ & $\begin{array}{l}\text { Vehicles' } \\
\text { number }\end{array}$ & $\begin{array}{c}\text { Satellites number: } \\
\text { open satellites/number of } \\
\text { assigned customers }\end{array}$ & TLR & VLR \\
\hline \multirow{3}{*}{ F1 } & C_min & 388 & 2 & 6 & $2: S 1 / 9 ; S 3 / 11$ & $55,80 \%$ & $78,67 \%$ \\
\hline & Em_min & 356 & 2 & 7 & $2: S 1 / 12 ; S 4 / 8$ & $55,80 \%$ & $78,65 \%$ \\
\hline & Soc_max & 769 & 2 & 6 & $2: S 2 / 3 ; S 3 / 17$ & $55,80 \%$ & $95,00 \%$ \\
\hline \multirow{3}{*}{$\mathrm{F} 2$} & C_min & 247 & 1 & 3 & 1: $S 1 / 12$ & $54,00 \%$ & $90,00 \%$ \\
\hline & Em_min & 167 & 1 & 3 & 1: $S 3 / 12$ & $54,00 \%$ & $90,00 \%$ \\
\hline & Soc_max & 167 & 1 & 3 & 1: $S 3 / 12$ & $54,00 \%$ & $90,00 \%$ \\
\hline \multirow{3}{*}{ F3 } & C_min & 170 & 1 & 2 & 1: $S 1 / 8$ & $30,20 \%$ & $50,50 \%$ \\
\hline & Em_min & 160 & 1 & 2 & 1: $S 4 / 8$ & $30,20 \%$ & $50,50 \%$ \\
\hline & Soc_max & 366 & 1 & 2 & 1: $S 3 / 8$ & $30,20 \%$ & $50,50 \%$ \\
\hline \multirow{3}{*}{$\begin{array}{l}\text { Total NCS }=F 1 \\
+F 2+F 3\end{array}$} & C_min & 805 & 4 & 11 & 2: S1/29; S3/11 & $46,67 \%$ & $72,83 \%$ \\
\hline & Em_min & 683 & 4 & 12 & 3: $S 1 / 12 ; S 4 / 16 ; S 3 / 12$ & $46,67 \%$ & $73,05 \%$ \\
\hline & Soc_max & 1302 & 4 & 11 & $2: S 2 / 3 ; S 3 / 37$ & $46,67 \%$ & $78,50 \%$ \\
\hline
\end{tabular}

TLR: load rate of tracks; VLR: load rate of vehicle.

cost minimizing case (C_min), emission minimizing case (Em_min), and social impact maximization case (Soc_max). The obtained results are presented in Tables 6 and 7 and Figure 3.

It can be seen that the cooperative scenario outperforms the noncooperative one in C_min and Em_min cases. When optimization is based on cost, $23,14 \%$ total cost and $8,45 \%$ total $\mathrm{CO} 2$ emissions reductions are obtained through horizontal collaboration. Based on $\mathrm{CO} 2$ emissions optimization, $12,01 \%$ total cost and 52,90\% total CO2 emissions reductions are obtained (see Figure 3).

As shown in Table 7, this finding can be explained by the reduction in the travelled distances and the number of vehicles due to the new allocation of customers to satellites and the increase of the load rates of vehicles. The number of trucks remained stable because, at the first level, each supplier takes charge of transporting their goods to the satellites.
From obtained results, in the collaborative scenario, if the cost values are used as benchmarks, a $77,37 \%$ reduction in carbon emissions can be achieved at $40,26 \%$ increase in the cost of the C_min case.

The results illustrate the negative effect of collaboration between the suppliers in Soc_max case in terms of cost and the number of created job opportunities. This is due to the fact of opining more warehouses and the aggregation of transported flows. All these aspects make the solution obtained in Soc_max case nonimplemented at the reality.

(3) Cost, CO2 Emissions, and Job Opportunities Allocation with Shapley Value Method. The partners are not, generally, interested in the profits generated by the entire alliance but in the impact of the cooperation on their own P\&L (profit and lost) instead. Then, before the companies agree to participate in a horizontal cooperation scheme, an estimation of the 
TABLE 6: Comparison between collaborative and noncollaborative scenarios in the extreme solutions.

\begin{tabular}{|c|c|c|c|c|c|c|c|}
\hline Objectives & Scenarios & Cost & $\begin{array}{c}\text { Emissions } \\
\text { (gCO } 2)\end{array}$ & Social impact & Cost gains & Emissions gains & Social impact gain \\
\hline \multirow{2}{*}{ C_min } & NCS & 2245 & 151656 & 37 & \multirow{2}{*}{$23,14 \%$} & \multirow{2}{*}{$8,45 \%$} & \multirow{2}{*}{$0 \%$} \\
\hline & CS & 1726 & 138836 & 37 & & & \\
\hline \multirow{2}{*}{ Em_min } & NCS & 2752 & 66714 & 38 & \multirow{2}{*}{$12,01 \%$} & \multirow{2}{*}{$52,90 \%$} & \multirow{2}{*}{$-2,63 \%$} \\
\hline & CS & 2421 & 31422 & 37 & & & \\
\hline \multirow{2}{*}{ Soc_max } & NCS & 3750 & 199425 & 40 & \multirow{2}{*}{$-2,69 \%$} & \multirow{2}{*}{$8,36 \%$} & \multirow{2}{*}{$-5 \%$} \\
\hline & CS & 3851 & 182751 & 38 & & & \\
\hline
\end{tabular}

TABLE 7: Summary results for base case of collaborative scenario.

\begin{tabular}{|c|c|c|c|c|c|c|c|}
\hline & Scenario & $\begin{array}{c}\text { Travelled } \\
\text { distances } \\
(\mathrm{Km})\end{array}$ & $\begin{array}{l}\text { Trucks } \\
\text { number }\end{array}$ & $\begin{array}{l}\text { Vehicles } \\
\text { number }\end{array}$ & $\begin{array}{c}\text { Satellites number: } \\
\text { open satellites/number of } \\
\text { assigned customers }\end{array}$ & (TLR) & (VLR) \\
\hline \multirow{3}{*}{ NCS } & C_min & 805 & 4 & 11 & $2: S 1 / 29 ; S 3 / 11$ & $46,67 \%$ & $72,83 \%$ \\
\hline & Em_min & 683 & 4 & 12 & 3: S1/12; S4/16; S3/12 & $46,67 \%$ & $73,05 \%$ \\
\hline & Soc_max & 1302 & 4 & 11 & $2: S 2 / 3 ; S 3 / 37$ & $46,67 \%$ & $78,50 \%$ \\
\hline \multirow{3}{*}{ CS } & C_min & 648 & 5 & 10 & $3: S 1 / 20 ; S 3 / 14 ; S 5 / 6$ & $48,67 \%$ & $92,92 \%$ \\
\hline & Em_min & 351 & 5 & 11 & $3: S 1 / 4 ; S 3 / 20 ; S 4 / 16$ & $44,47 \%$ & $79,00 \%$ \\
\hline & Soc_max & 1174 & 5 & 11 & 3: $S 2 / 19 ; S 3 / 19 ; S 4 / 2$ & $32,45 \%$ & $73,80 \%$ \\
\hline
\end{tabular}

TLR: load rate of tracks; VLR: load rate of vehicle.

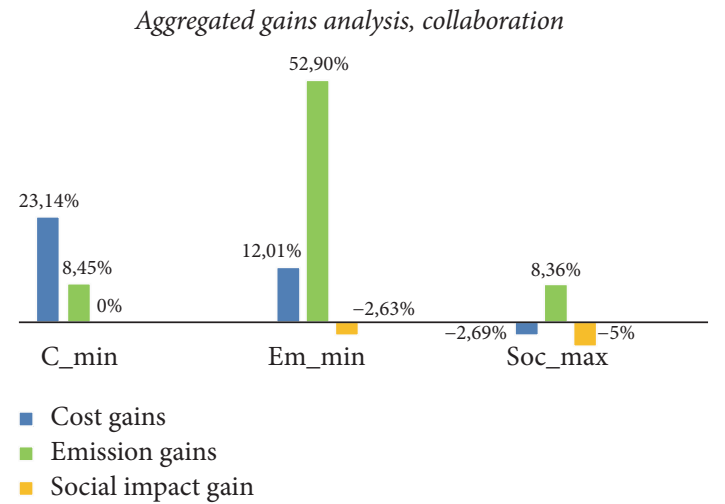

FIGURE 3: Aggregated gains analysis of extreme solutions after collaboration.

individual cost, $\mathrm{CO} 2$ emissions, and job opportunities savings must be available.

We allocate the collaborative gains with the Shapley value method for the three cases C_min, Em_min, and soc_max. To be able to divide the three metrics according to the Shapley value, the metrics of the subcoalitions are also determined by creating lists that contain orders of these subcoalitions and repeating precedent calculation. Results are presented in Figure 4.

In C_min and Em_min cases, results show that collaboration can generate more considerable reductions in cost and $\mathrm{CO} 2$ emissions rather than those that individual companies can achieve. From Figure 5, by comparing allocated gains to each supplier in the two cases of the collaborative scenario, we can observe that, in C_min case, gains related to cost and $\mathrm{CO} 2$ emissions change based on the supplier size. When the supplier size increases, the cost and CO2 emissions gains decrease because the big size supplier (F1) has more customers and delivered freight and then more cost was allocated to this supplier. In Em_min case, we cannot remark the same trend. For example, the medium size supplier (F2) has generated, on one hand, the higher $\mathrm{CO} 2$ emissions gain and on the other hand, the smaller cost gain. The big size supplier (F1) has generated the higher cost gain and the smaller CO2 emissions gain. F3 was the only supplier that improves their social impact after collaboration.

(4) Comparison between Allocation Methods. In order to help the coalition to evaluate other allocation mechanisms, we suggest to decision makers to compare the Shapley value method to the simple proportional allocation rules, especially, the volume-based allocation and linear rule method. According to the allocation method, a different division of the cost, $\mathrm{CO} 2$ emissions, and created job opportunities are realized. These differences between the allocation methods are demonstrated in Table 8. The example of the allocation of different metrics to supplier F1 in the scenario of cost minimization is shown in Figure 6. Figure 7 illustrates the repartition of cost, $\mathrm{CO} 2$ emissions, and job opportunities gains by the different methods.

The three allocation methods allocate less cost/emissions/ jobs to the smaller partners, F2 and F3, in favor of the big partner F1. The linear rule method uses the stand-alone cost/ emissions/jobs to define the relative importance of each partner. Thereby, the company with higher stand-alone costs/ emissions/jobs (F1) receives a bigger absolute part of the coalition cost/emissions/jobs. The volume-based allocation method allocates the cost/emissions of the coalition based on each partner's shipped volume. Then, partner with higher 
TABLE 8: Allocation of coalition cost, $\mathrm{CO} 2$ emissions, and job opportunities by different methods.

\begin{tabular}{|c|c|c|c|c|c|c|c|c|c|c|}
\hline & \multirow[b]{2}{*}{ Case } & \multicolumn{3}{|c|}{ Shapley value } & \multicolumn{3}{|c|}{ Volume-based allocation } & \multicolumn{3}{|c|}{ Linear rule } \\
\hline & & Cost $(€)$ & $\begin{array}{c}\text { Emissions } \\
\text { (g/CO2) }\end{array}$ & SI & Cost $(€)$ & $\begin{array}{c}\text { Emissions } \\
(\mathrm{g} / \mathrm{CO} 2)\end{array}$ & SI & Cost $(€)$ & $\begin{array}{c}\text { Emissions } \\
\text { (g/CO2) }\end{array}$ & SI \\
\hline \multirow{3}{*}{ F1 } & C_min & 1056 & 76481 & 24 & 1037 & 83391 & 22 & 969 & 74199 & 22 \\
\hline & Em_min & 1304 & 24902 & 23 & 1454 & 18873 & 22 & 1353 & 19096 & 21 \\
\hline & Soc_max & 2357 & 111853 & 23 & 2313 & 109769 & 23 & 2347 & 126797 & 22 \\
\hline \multirow{3}{*}{ F2 } & C_min & 440 & 42305 & 9 & 502 & 40351 & 11 & 477 & 42205 & 11 \\
\hline & Em_min & 683 & 3570 & 9 & 704 & 9132 & 11 & 627 & 6983 & 12 \\
\hline & Soc_max & 982 & 46597 & 10 & 1119 & 53114 & 11 & 732 & 13586 & 11 \\
\hline \multirow{3}{*}{ F3 } & C_min & 229 & 20049 & 4 & 188 & 15094 & 4 & 280 & 22432 & 4 \\
\hline & Em_min & 435 & 2950 & 5 & 263 & 3416 & 4 & 441 & 5343 & 4 \\
\hline & Soc_max & 512 & 24301 & 5 & 419 & 19869 & 4 & 772 & 42367 & 5 \\
\hline
\end{tabular}
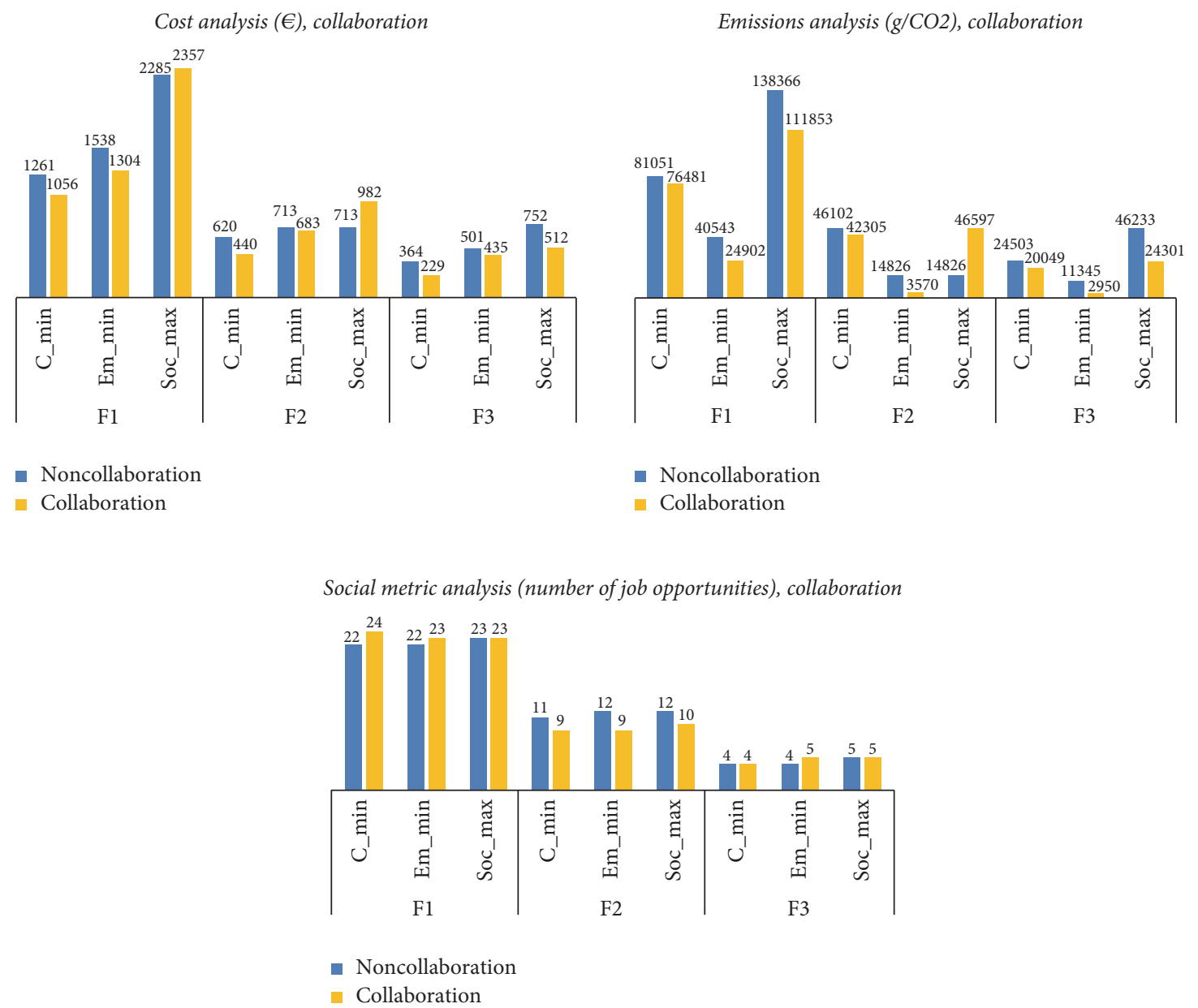

FIGURE 4: Comparison of cost, emissions, and social metric between collaborative and noncollaborative scenarios.

individual volume receives the higher part of the coalition cost/emissions/jobs. The Shapley value method tends to allocate more cost/emissions/jobs to partner F1, due to their higher stand-alone cost.

From Figure 7 , in the linear rule and Shapley value, no partner is allocated a negative profit when the total transportation costs and emissions are shared contrary to the volume-based method which allocates to supplier F1 a negative $\mathrm{CO} 2$ emissions gain in the $\mathrm{C}_{-}$min case. The linear rule divides the coalition gains to different partner in order to obtain equal savings.

The proportional cost allocation methods are simple and easy to communicate to the members of coalition but present some weakness. The volume-based allocation method is easy 
Gains analysis in C_min case

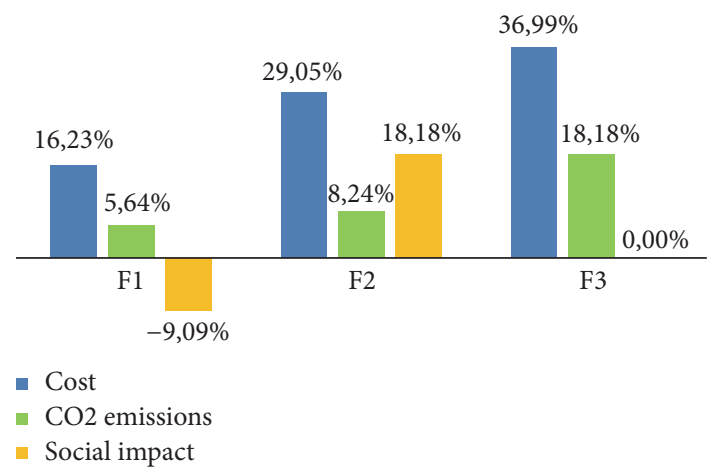

Gains analysis in Em_min case

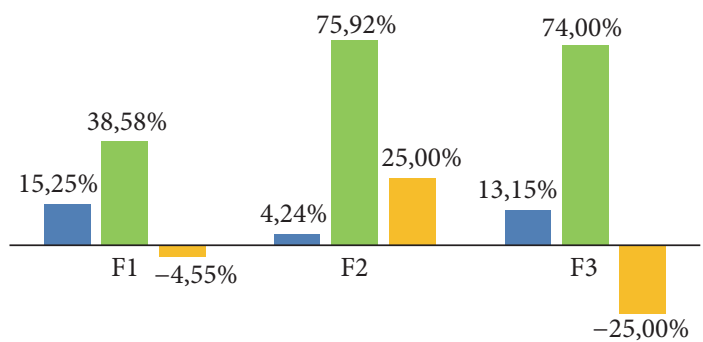

- Cost

- $\mathrm{CO} 2$ emissions

- Social impact

Gains analysis in Soc_max case

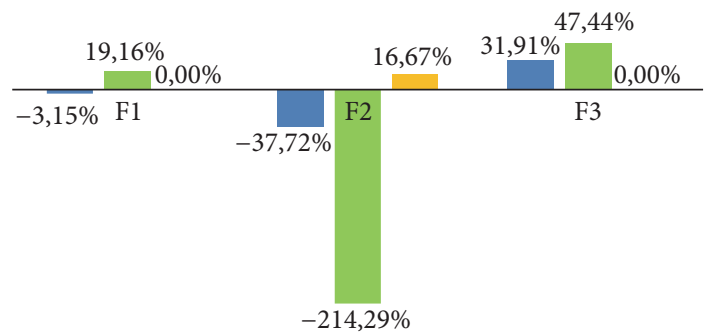

\footnotetext{
- Cost

- CO2 emissions

- Social impact
}

Figure 5: Gains analysis of extreme solutions in collaborative scenario for each partner.
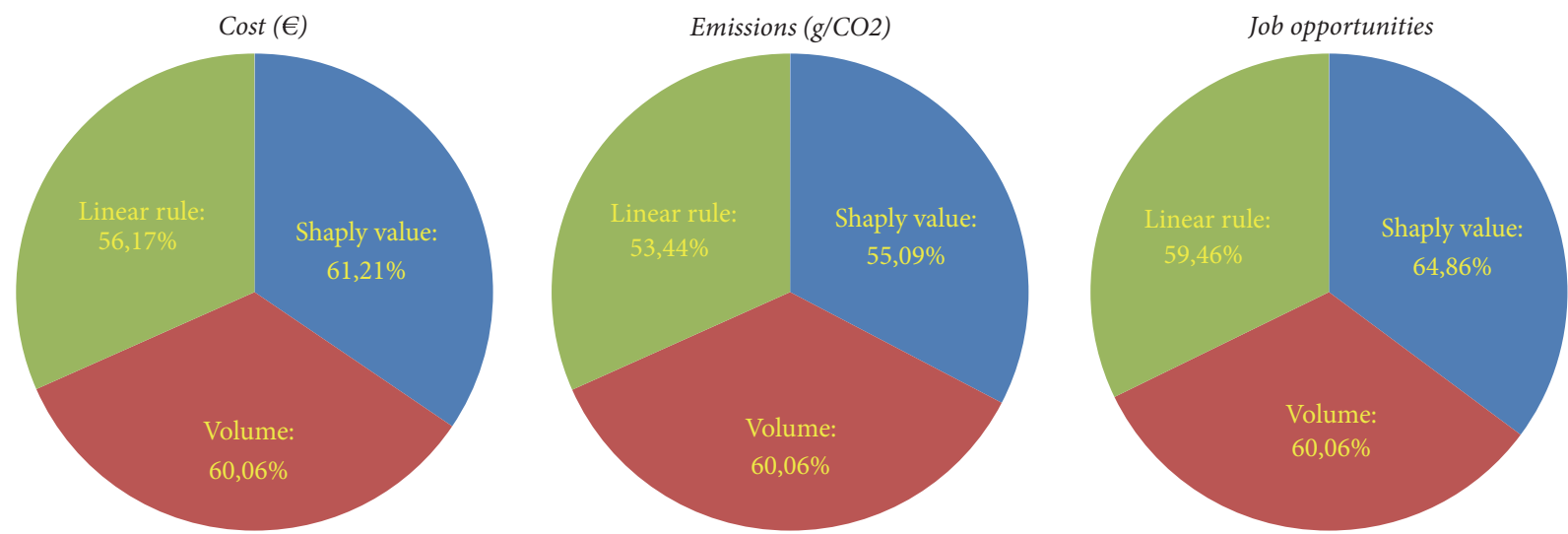

Figure 6: Allocation of coalition's cost, CO2 emissions, and job opportunities to supplier F1 by the different methods in the scenario of cost minimization.

to compute but can lead partners to lose as compared to when they operate alone. Moreover, this method does not take into consideration the geographical distribution of the demand points.

The linear rule divides the coalition gains to different partner in order to obtain equal savings for all partners. This method cannot be seen as fair since the big size company offers more opportunities to optimize and to negotiate better price with carriers than a smaller company.

The Shapley value is based on the marginal cost/emissions/ job of the different partners in every possible subcoalition and then the efficiency of single partner is desirable. The Shapley value gives incentives to be flexible and collaborative in our case study.

Defryn et al. [63] acknowledge the need to select a gain or cost allocation mechanism on a case-by-case approach. As every allocation method is based on certain partner and coalition characteristics, incentives are given when selecting a certain mechanism [28].

4.2.2. Multiobjective Approach. Decision makers are interested in analyzing all three objectives simultaneously so as 


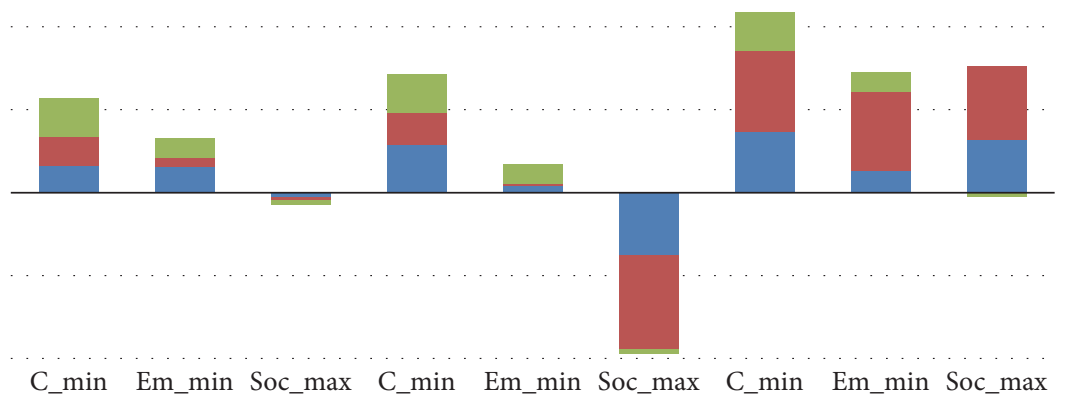

\begin{tabular}{lccccccccc}
\multicolumn{3}{c}{} & \multicolumn{1}{c}{$\mathrm{F} 1$} & \multicolumn{3}{c}{$\mathrm{F} 2$} & \multicolumn{3}{c}{$\mathrm{F} 3$} \\
\hline - Linear rule & $23,14 \%$ & $12,00 \%$ & $-2,69 \%$ & $23,14 \%$ & $12,00 \%$ & $-2,69 \%$ & $23,14 \%$ & $12,00 \%$ & $-2,69 \%$ \\
- Volume & $17,79 \%$ & $5,45 \%$ & $-1,23 \%$ & $19,09 \%$ & $1,31 \%$ & $-56,98 \%$ & $48,45 \%$ & $47,46 \%$ & $44,32 \%$ \\
- Shapley value & $16,23 \%$ & $15,25 \%$ & $-3,15 \%$ & $29,05 \%$ & $4,24 \%$ & $-37,72 \%$ & $36,99 \%$ & $13,15 \%$ & $31,91 \%$
\end{tabular}

CO2 emissions gains analysis (\%)

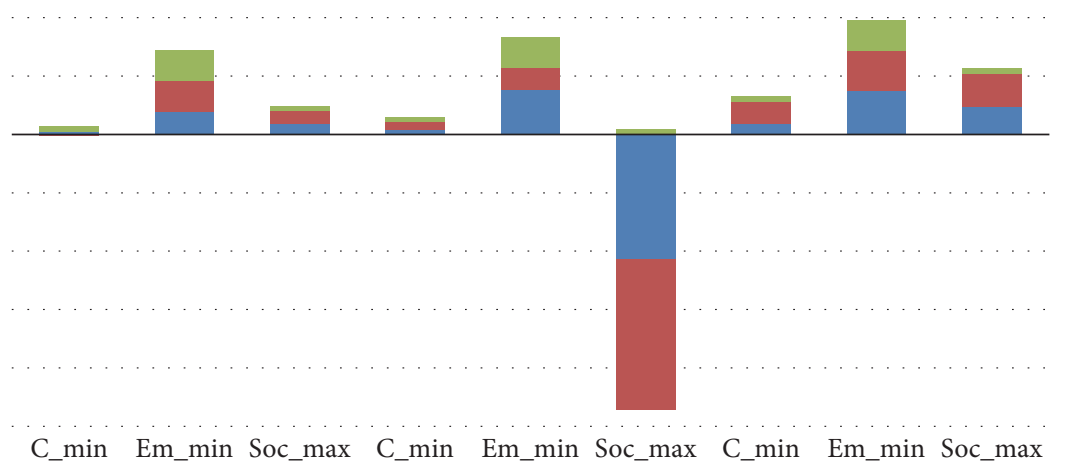

\begin{tabular}{lccccccccc}
\multicolumn{3}{c}{$\mathrm{F} 1$} & \multicolumn{3}{c}{$\mathrm{F} 2$} & \multicolumn{3}{c}{$\mathrm{F} 3$} \\
\hline Linear rule & $8,45 \%$ & $52,90 \%$ & $8,36 \%$ & $8,45 \%$ & $52,90 \%$ & $8,36 \%$ & $8,45 \%$ & $52,90 \%$ & $8,36 \%$ \\
- Volume & $-2,89 \%$ & $53,45 \%$ & $20,67 \%$ & $12,48 \%$ & $38,40 \%$ & $-258,25 \%$ & $38,40 \%$ & $69,89 \%$ & $57,03 \%$ \\
- Shapley value & $5,64 \%$ & $38,58 \%$ & $19,16 \%$ & $8,24 \%$ & $75,92 \%$ & $-214,29 \%$ & $18,18 \%$ & $74,00 \%$ & $47,44 \%$
\end{tabular}

Job opportunities gains analysis (\%)

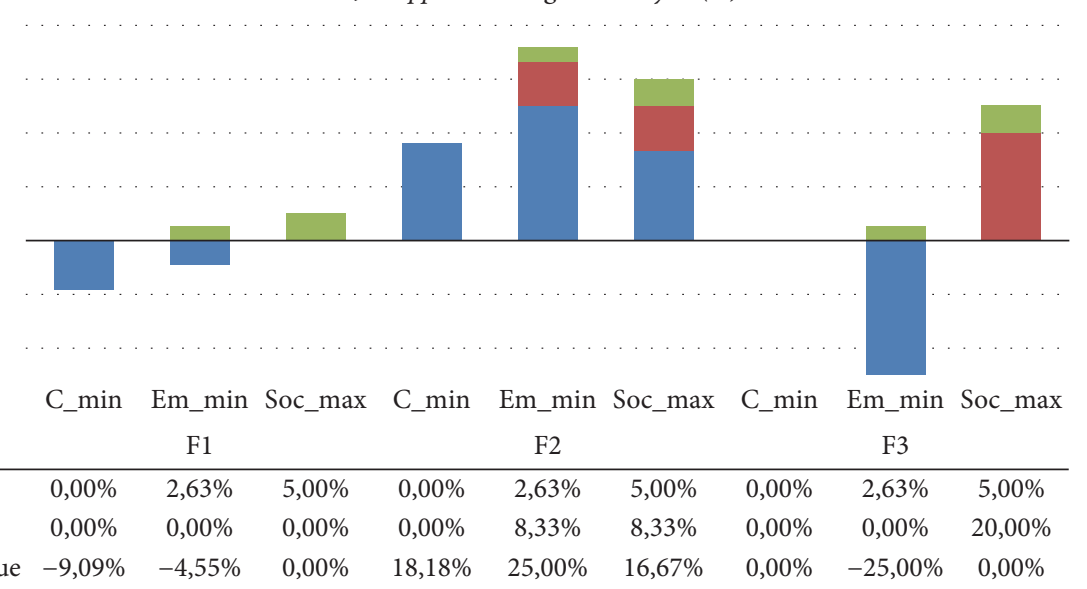

FIGURE 7: Repartition of cost, CO2 emissions, and job opportunities gains by the different allocation methods. 
TABLE 9: Payoff table in collaboration scenario.

\begin{tabular}{lccc}
\hline $\begin{array}{l}\text { objective } \\
\text { function }\end{array}$ & Cost $(€)$ & $\begin{array}{c}\text { Emissions } \\
(\mathrm{g} / \mathrm{CO} 2)\end{array}$ & $\begin{array}{c}\text { Job } \\
\text { opportunities }\end{array}$ \\
\hline C_min & 1726 & 138836 & 37 \\
Em_min & 2422 & 31422 & 37 \\
Soc_max & 3851 & 182751 & 38 \\
\hline
\end{tabular}

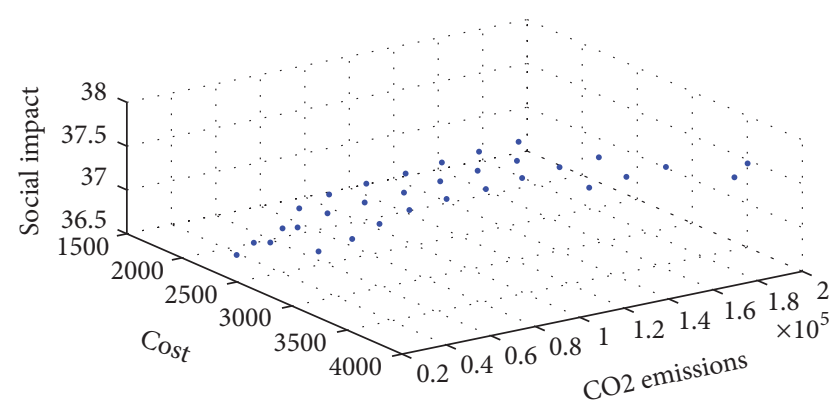

FIgURE 8: Tradeoffs between transportation cost, CO2 emissions, and created job in collaborative scenario.

to establish possible solutions of compromise. Multiobjective optimization is a powerful tool for coping with tradeoffs among conflicting objectives. In our problem, decision makers do not completely know the importance of each objective and want to study the sensitivity of the total transportation cost versus $\mathrm{CO} 2$ emissions reduction and social impact improvement. Thereby, a set of efficient solutions and the Pareto frontier can be generated using $\varepsilon$-constraint method. Cost objective is selected for optimization while $\mathrm{CO} 2$ emissions and created job are reformulated as constraints. By progressively changing the constraint values, $\varepsilon$, which represent the limit on $\mathrm{CO} 2$ emissions and job created, different points on the Pareto-front could be sampled. Defining the extremes of the Pareto-front, the range of different objective functions could be calculated and constraint values selected accordingly. The total of 54 combinations of environmental and social bounds are considered to minimize transportation cost in the $\varepsilon$-constraint method. The payoff and Pareto frontier derived from generated implementation of instances are given in Table 9 and Figure 8.

From obtained results, tradeoffs exist between economic, environmental, and social objectives. The three objectives are in conflict with each other as the one gets more desirable values, and the others fall into more undesirable values. The partners should pay more to protect environment and social aspects compared to a situation in which only economic metric is taken into account. For the coalition (suppliers), it is important to estimate the impact of the selected solution on their cost in the case of collaboration under multiobjective approach compared to the cost value of the most costoptimum solution in case of noncollaboration.

For this reason, we compare the obtained solution from the implementation of the 54 combinations of environmental and social bounds with the solution obtained when the model is solved only according to cost objective function (C_min case) of noncollaborative scenario. The selected solution has to guarantee the positive gains in the economic as well as in the environmental performance when compared to the noncollaborative scenario. For the social aspect, partners want at least to conserve the same number of created jobs compared to the noncollaborative scenario. Solutions that perform better in this criterion besides generated gains are presented in Table 10. For decision makers, the selection of a solution of compromise is performed according to the coalition's economic, environmental, and social goals.

\section{Concluding Remarks and Further Research}

In this article, the economic, environmental, and social effect of joint vehicle routing and depot location in urban road freight transportation under horizontal collaboration is examined by presenting a holistic view of the problem. We proposed a preliminary decision support tool based on three objectives' mixed integer linear model, minimizing the cost and $\mathrm{CO} 2$ emissions of the transportation and maximizing the created variable job opportunities. In this quantitative analysis, we used a known realistic set of benchmarks for the two-echelon location routing problem, 2E-LRP, to illustrate the horizontal collaboration. This set is reflecting real distribution urban area. To obtain the tradeoffs between different types of objectives, the model was solved with the $\varepsilon$-constraint method.

Results show that a collaborative approach can reduce $\mathrm{CO} 2$ emissions, transportation cost, and the number of used vehicles and indirectly minimize nuisance and traffic congestion in cities. However, collaboration can affect negatively the created job opportunities. We suggested to decision makers a comparison between well-known allocation methods to evaluate the effect of chosen method in allocated gains. Reviewing current literature reveals that the results presented in this article display clear similarities with the conclusions drawn in other logistics collaboration contexts.

For further research we believe that it might be useful to study the sensitivity of the results when using heterogeneous vehicles and trucks or changing model's parameters to investigate the effect of these changes in generated gains. Also the complexity of the model adopted requires choosing a heuristic resolution, especially for instances with a large number of served points.

\section{Notations}

Sets

$K=\{1,2, \ldots, F\}: \quad$ Set of factories $k$

$J=\{1,2, \ldots, W\}: \quad$ Set of satellites $j$

$I=\{W+1, \ldots, W+S\}$ : Set of clients $i$

$P=\{1, \ldots, F\}: \quad$ Set of products $p$.

Auxiliary Sets

$h, l$ : Delivery point.

Model Parameters

$q_{(i p)}: \quad$ Demand of client $i$ of product $p$

$F$ cap $_{(k)}$ : Capacity of factory $k$ 
TABLE 10: Best solution selected among the possible solutions.

\begin{tabular}{lcccccc}
\hline \multirow{2}{*}{ Cost } & Value $(€)$ & 1823 & 1876 & 1901 & 1945 & 2056 \\
& Gains & $18,80 \%$ & $16,44 \%$ & $15,32 \%$ & $13,36 \%$ & $8,42 \%$ \\
\hline \multirow{2}{*}{ Emissions } & Value (g/CO2) & 144919 & 126003 & 107086 & 88170 & 69254 \\
& Gains & $4,44 \%$ & $16,92 \%$ & $29,39 \%$ & $41,86 \%$ & $54,33 \%$ \\
\hline \multirow{2}{*}{ Job opportunities } & Value & 37 & 37 & 37 & 37 & 37 \\
& Gains & $0 \%$ & $0 \%$ & $0 \%$ & $0 \%$ \\
\hline
\end{tabular}

$W$ cap $_{(j)}$ : Capacity of satellite $j$

Tcap: Capacity of truck (1st-level vehicle)

$V$ cap: $\quad$ Capacity of vehicle (2nd-level vehicle)

FCT: $\quad$ Fixed costs of truck (1st-level vehicle)

FCV: $\quad$ Fixed costs of vehicle (2nd-level vehicle)

$H_{j}$ : $\quad$ Fixed cost of opening and operating the satellite $j$

$L_{j}$ : $\quad$ Unit transshipment cost of freight in satellite $j$

$C_{(k j)}$ : $\quad$ Cost of sending a truck from factory $k$ to satellite $j$

$\mathrm{OV}_{j}$ : $\quad$ Number of variable job opportunities created through depot $j$

$C 1_{(j i)}$ : Cost of visiting customer $i$ just after the satellite $j$

$C 2_{(i j)}: \quad$ Cost of visiting satellite $j$ just after customer $i$

$C 3_{(i l)}: \quad$ Cost of visiting customer $l$ just after customer $i$

$d_{(j i)}$ : $\quad$ Distance between satellite $j$ and delivery point $i$

$d_{(i l j)}$ : $\quad$ Distance between delivery point $i$ and delivery point $l$ in each route of $j$

$d_{(i j)}: \quad$ Distance between delivery point $i$ and satellite $j$

$E_{\left(T_{-} \text {empty) }\right.}$ : Emission of an empty truck

$E_{\left(T_{-} \text {full }\right)}:$ Emission of full truckload of a truck

$E_{\left(V_{-} \text {empty) }\right.}$ : Emission of an empty vehicle

$E_{\left(V_{-} \text {full) }\right.}:$ Emission of full truckload of a vehicle

$V: \quad$ Average vehicle travel speed

$T$ : $\quad$ Maximum route time.

\section{Decision Variables}

$f_{(k j)}$ : Quantity of the product sent from factory $k$ to satellite $j$

$N_{(k j)}$ : Number of trucks sent from factory $k$ to satellite $j$

$R_{(j)}$ : Number of vehicles assigned to the open satellite $j$

$y_{j}: \begin{cases}1 & \text { if satellite } j \text { is open } \\ 0 & \text { otherwise }\end{cases}$

$w_{i j}: \begin{cases}1 & \text { if client is assigned to satellite } j \\ 0 & \text { otherwise }\end{cases}$

$x 1_{j i}: \begin{cases}1 & \text { if } i \text { is the first customer in each route of } j \\ 0 & \text { otherwise }\end{cases}$

$x 2_{i j}: \begin{cases}1 & \text { if } i \text { is the last customer in each route of } j \\ 0 & \text { otherwise }\end{cases}$

$x 3_{i h j}:\left\{\begin{array}{l}1 \text { if customer } l \text { is visited after customer } i \text { in } \\ \text { each route of } j \\ 0 \begin{array}{l}\text { otherwise }\end{array}\end{array}\right.$

$U_{\text {pihj }}:$ Load of product $p$ on vehicle which goes from customer $i$ to costumer $l$ in each route of $j$

$U_{p j i}$ : Load of product $p$ on vehicle which goes from satellite $j$ to first customer $i$ in each route of $j$.

\section{Conflicts of Interest}

The authors declare that there are no conflicts of interest regarding the publication of this paper.

\section{References}

[1] European Commission, Road Transport: A Change of Gear, 2012, Publications Office of the European Union, 2012.

[2] F. Cruijssen, Horizontal Cooperation in Transport and Logistics [Ph.D. thesis], 2006, published $\mathrm{PhD}$ thesis.

[3] J. Gonzalez-Feliu and J. Salanova, "Defining and evaluating collaborative urban freight transportation systems," Procedia Social and Behavioral Sciences, vol. 39, pp. 172-183, 2012.

[4] S. Pan, E. Ballot, F. Fontane, and D. Hakimi, "Environmental and economic issues arising from the pooling of SMEs' supply chains: case study of the food industry in western France," Flexible Services and Manufacturing Journal, vol. 26, no. 1-2, pp. 92-118, 2014.

[5] W. S. Yi, N. B. M. Jamal, and T. A. Chin, "Exploring supply chain collaboration: evolution, definition and benefits," The Social Sciences, vol. 11, no. 11, pp. 2845-2851, 2016, http://medwelljournals.com/abstract/?doi=sscience.2016.2845.2851.

[6] N. H. Taieb and H. Affes, "Approaches to improve the performance of the collaborative supply chain management: Literature review," in Proceedings of the 2013 International Conference on Advanced Logistics and Transport, ICALT 2013, pp. 440-445, tun, May 2013.

[7] R. Leitner, F. Meizer, M. Prochazka, and W. Sihn, "Structural concepts for horizontal cooperation to increase efficiency in logistics," CIRP Journal of Manufacturing Science and Technology, vol. 4, no. 3, pp. 332-337, 2011.

[8] L. E. Amer and A. B. Eltawil, "Analysis of quantitative models of horizontal collaboration in supply chain network design: towards 'green collaborative' strategies," in Proceedings of the 5th International Conference on Industrial Engineering and Operations Management, IEOM 2015, Dubai, UAE, March 2015.

[9] A. Moutaoukil, R. Derrouich, G. Neubert, I. Fayol, and C. Fauriel, "Modélisation d'une stratégie de mutualisation logistique en intégrant les objectifs de Développement Durable pour des PME agroalimentaires," in Proceedings of the 13e Congrés International de Génie Industriel (CIGI'13), La Rochelle, France, Jun 2013.

[10] M. Soysal, J. M. Bloemhof-Ruwaard, R. Haijema, and J. G. A. J. van der Vorst, "Modeling a green inventory routing problem for perishable products with horizontal collaboration," Computers and Operations Research, 2016.

[11] L. E. Amer and A. B. Eltawil, "Collaborative sustainable supply chain network design: state of the art and solution framework," 
in Proceedings of the 44th International Conference on Computers \& Industrial Engineering, CIE 2014, pp. 479-493, Istanbul, Turkey, 2014.

[12] N. Danloup, H. Allaoui, and G. Goncalves, "Literature review on or tools and methods for collaboration in supply chain," in Proceedings of the 2013 International Conference on Industrial Engineering and Systems Management, IEEE - IESM 2013, October 2013.

[13] A. Muñoz-Villamizar, J. R. Montoya-Torres, and C. A. VegaMejía, "Non-collaborative versus collaborative last-mile delivery in urban systems with stochastic demands," in Proceedings of the 7th CIRP Industrial Product-Service Systems Conference, IPSS 2015, pp. 263-268, May 2015.

[14] J. R. Montoya-Torres, A. Muñoz-Villamizar, and C. A. VegaMejía, "On the impact of collaborative strategies for goods delivery in city logistics," Production Planning and Control, vol. 27, no. 6, pp. 443-455, 2016.

[15] L. Zhu and D. Hu, "Sustainable logistics network modeling for enterprise supply chain," Mathematical Problems in Engineering, vol. 2017, 11 pages, 2017.

[16] L. Chen, X. Zhao, O. Tang, L. Price, S. Zhang, and W. Zhu, "Supply chain collaboration for sustainability: a literature review and future research agenda," International Journal of Production Economics, 2017.

[17] J. R. Montoya-Torres, "Designing sustainable supply chains based on the triple bottom line approach," in Proceedings of the 4th IEEE International Conference on Advanced Logistics and Transport, IEEE ICALT 2015, pp. 1-6, May 2015.

[18] J. Gonzalez-Feliu, "A la recherche d une mutualisation des livraisons en milieu urbain?: le cas du groupe," Revue Française de Gestion Industrielle, pp. 1-20, 2010.

[19] G. Nagy and S. d. Salhi, "Location-routing: issues, models and methods," European Journal of Operational Research, vol. 177, no. 2, pp. 649-672, 2007.

[20] C. Prodhon, 2006, Le Problème de Localisation-Routage.

[21] "Comments on the draft guidelines on the applicability of article 101 of the treaty on the functioning of the european union to horizontal co-operation agreements," European Competition Journal, vol. 6, no. 2, pp. 507-540, 2010.

[22] E. Pérez-Bernabeu, A. A. Juan, J. Faulin, and B. B. Barrios, "Horizontal cooperation in road transportation: a case illustrating savings in distances and greenhouse gas emissions," International Transactions in Operational Research, vol. 22, no. 3, pp. 585-606, 2015.

[23] A. A. Juan, J. Faulin, E. Pérez-Bernabeu, and N. Jozefowiez, "Horizontal cooperation in vehicle routing problems with backhauling and environmental criteria," Procedia - Social and Behavioral Sciences, vol. 111, pp. 1133-1141, 2014.

[24] C. Vanovermeire and K. Sörensen, "Measuring and rewarding flexibility in collaborative distribution, including two-partner coalitions," European Journal of Operational Research, vol. 239, no. 1, pp. 157-165, 2014.

[25] M. Guajardo, K. Jörnsten, and M. Rönnqvist, "Constructive and blocking power in collaborative transportation," OR Spectrum, vol. 38, no. 1, pp. 25-50, 2016.

[26] N. Danloup, V. Mirzabeiki, H. Allaoui, G. Goncalves, D. Julien, and C. Mena, "Reducing transportation greenhouse gas emissions with collaborative distribution: a case study," Management Research Review, vol. 38, no. 10, pp. 1049-1067, 2015.
[27] C. Defryn, K. Sörensen, and T. Cornelissens, "The selective vehicle routing problem in a collaborative environment," European Journal of Operational Research, vol. 250, no. 2, pp. 400411, 2016.

[28] C. Defryn, C. Vanovermeire, and K. Sörensen, "Gain sharing in horizontal logistic co-operation: a case study in the fresh fruit and vegetables sector," Sustainable Logistics and Supply Chains: Innovations and Integral Approaches, pp. 75-89, 2015.

[29] X. Tang, F. Lehud, and O. Pton, "Location of distribution centers in a multi-period collaborative distribution network," Electronic Notes in Discrete Mathematics, vol. 52, pp. 293-300, 2015.

[30] G. Kuyzu, "Lane covering with partner bounds in collaborative truckload transportation procurement," Computers \& Operations Research, vol. 77, pp. 32-43, 2017.

[31] H. Park, D. Park, and I.-J. Jeong, "An effects analysis of logistics collaboration in last-mile networks for CEP delivery services," Transport Policy, vol. 50, pp. 115-125, 2016.

[32] A. Muñoz-Villamizar, J. R. Montoya-Torres, and J. Faulin, "Impact of the use of electric vehicles in collaborative urban transport networks: a case study," Transportation Research Part D: Transport and Environment, vol. 50, pp. 40-54, 2017.

[33] H. Ouhader and M. El kyal, "Horizontal collaborative supply chain network design: mathematical programming model," in Proceedings of the 2nd International Conference of Project and Logistic - PROLOG2016, Agadir, Morocco, 2016.

[34] H. Ouhader and M. Elkyal, "A two-echelon location-routing model for designing a pooled distribution supply chain," in Proceedings of the 3rd IEEE International Conference on Logistics Operations Management, GOL 2016, pp. 1-19, Fes, Morocco, May 2016.

[35] R. Cuda, G. Guastaroba, and M. G. Speranza, "A survey on twoechelon routing problems," Computers \& Operations Research, vol. 55, pp. 185-199, 2015.

[36] V.-P. Nguyen, C. Prins, and C. Prodhon, "Solving the twoechelon location routing problem by a GRASP reinforced by a learning process and path relinking," European Journal of Operational Research, vol. 216, no. 1, pp. 113-126, 2012.

[37] M. Drexl and M. Schneider, "A survey of variants and extensions of the location-routing problem," European Journal of Operational Research, vol. 241, no. 2, pp. 283-308, 2015.

[38] C. Prodhon and C. Prins, "A survey of recent research on location-routing problems," European Journal of Operational Research, vol. 238, no. 1, pp. 1-17, 2014.

[39] M. Boccia, T. G. Crainic, A. Sforza, and C. Sterle, Flow Intercepting Formulation and Branch-and-Cut Algorithm MultiCommodity Location-Routing, Centre Interuniversitaire de Recherche sur les Réseaux d'Entreprise, la Logistique et le Transport, 2016.

[40] M. Boccia, T. G. Crainic, A. Sforza, and C. Sterle, "A metaheuristic for a two echelon location-routing problem," Lecture Notes in Computer Science, vol. 6049, pp. 288-301, 2010.

[41] B. Mota, M. Isabel, A. Carvalho, and A. P. Barbosa-povoa, "Towards supply chain sustainability: economic, environmental and social design and planning," Journal of Cleaner Production, vol. 105, pp. 14-27, 2014.

[42] S. Seuring and M. Müller, "From a literature review to a conceptual framework for sustainable supply chain management," Journal of Cleaner Production, vol. 16, no. 15, pp. 1699-1710, 2008.

[43] J. C. Velázquez-Martínez, J. C. Fransoo, E. E. Blanco, and J. Mora-Vargas, "The impact of carbon footprinting aggregation 
on realizing emission reduction targets," Flexible Services and Manufacturing Journal, vol. 26, no. 1-2, pp. 196-220, 2014.

[44] S. Ubeda, F. J. Arcelus, and J. Faulin, "Green logistics at eroski: a case study," International Journal of Production Economics, vol. 131, no. 1, pp. 44-51, 2011.

[45] E. Demir, T. Bektaş, and G. Laporte, "A review of recent research on green road freight transportation," European Journal of Operational Research, vol. 237, no. 3, pp. 775-793, 2014.

[46] H. W. Kopfer, J. Schönberger, and H. Kopfer, "Reducing greenhouse gas emissions of a heterogeneous vehicle fleet," Flexible Services and Manufacturing Journal, vol. 26, no. 1-2, pp. 221-248, 2014.

[47] T. Bektas, E. Demir, and G. Laporte, "Green Transportation Logistics," in Green Transportation Logistics, vol. 226 of International Series in Operations Research \& Management Science, pp. 243-265, Springer, 2016.

[48] J. Hickman, "Methodology for calculating transport emissions and energy consumption," Tech. Rep., Transportation Research Laboratory, Crowthorne, 1999.

[49] A. Moutaoukil, G. Neubert, and R. Derrouiche, "Urban freight distribution: The impact of delivery time on sustainability," IFAC-PapersOnLine, vol. 28, no. 3, pp. 2368-2373, 2015.

[50] S. Pan, E. Ballot, and F. Fontane, "The reduction of greenhouse gas emissions from freight transport by pooling supply chains," International Journal of Production Economics, vol. 143, no. 1, pp. 86-94, 2013.

[51] A. Moutaoukil, G. Neubert, and R. Derrouiche, "A comparison of homogeneous and heterogeneous vehicle fleet size in green vehicle routing problem," IFIP Advances in Information and Communication Technology, vol. 439, no. 2, pp. 450-457, 2014.

[52] K. Devika, A. Jafarian, and V. Nourbakhsh, "Designing a sustainable closed-loop supply chain network based on triple bottom line approach: a comparison of metaheuristics hybridization techniques," European Journal of Operational Research, vol. 235, no. 3, pp. 594-615, 2014.

[53] Y. Bouchery, A. Ghaffari, Z. Jemai, and J. Fransoo, "Sustainable transportation and order quantity: insights from multiobjective optimization," Flexible Services and Manufacturing Journal, vol. 28, no. 3, pp. 367-396, 2016.

[54] C. Vanovermeire, K. Sörensen, A. Van Breedam, B. Vannieuwenhuyse, and S. Verstrepen, "Horizontal logistics collaboration: decreasing costs through flexibility and an adequate cost allocation strategy," International Journal of Logistics Research and Applications, vol. 17, no. 4, pp. 339-355, 2014.

[55] F. Cruijssen and A. BV, $\mathrm{CO}^{3}$ Position Paper: Framework for Collaboration, 2013.

[56] M. Guajardo and M. Rönnqvist, "A review on cost allocation methods in collaborative transportation," International Transactions in Operational Research, vol. 23, no. 3, pp. 371-392, 2016.

[57] F. Kellner and A. Otto, "Allocating CO 2 emissions to shipments in road freight transportation," Journal of Management Control, vol. 22, no. 4, pp. 451-479, 2012.

[58] L. S. Shapley, "A value for n-person games," Annals of Mathematical Studies, vol. 28, pp. 307-317, 1953.

[59] V. F. Yu, P. Jewpanya, and V. Kachitvichyanukul, "Particle swarm optimization for the multi-period cross-docking distribution problem with time windows," International Journal of Production Research, vol. 54, no. 2, pp. 509-525, 2016.

[60] M. Soysal, J. M. Bloemhof-Ruwaard, R. Haijema, and J. G. A. J. Van Der Vorst, "Modeling an inventory routing problem for perishable products with environmental considerations and demand uncertainty," International Journal of Production Economics, vol. 164, pp. 118-133, 2015.

[61] C. Sterle, Location-Routing models and methods for Freight Distribution and Infomobility in City Logistics [M.S. thesis], 2009, Université a degli Studi di Napoli "Federico II" Dipartimento di Informatica e Sistemistica Dottorato di Ricerca in Ingegneria Informatica ed Automatica.

[62] C. Contardo, V. Hemmelmayr, and T. G. Crainic, "Lower and upper bounds for the two-echelon capacitated location-routing problem," Computers \& Operations Research, vol. 39, no. 12, pp. 3185-3199, 2012.

[63] C. Defryn, C. Vanovermeire, and K. Sörensen, "Gain sharing in horizontal logistic co-operation: a case study in the fresh fruit and vegetables sector," in Sustainable Logistics and Supply Chains, pp. 75-89, 2014. 


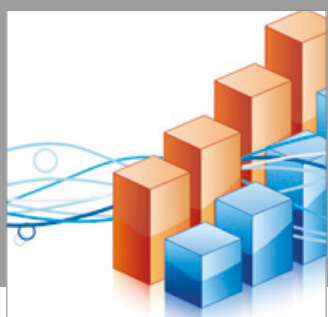

Advances in

Operations Research

vatersals

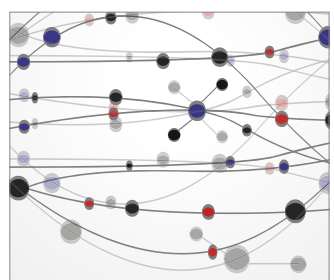

\section{The Scientific} World Journal
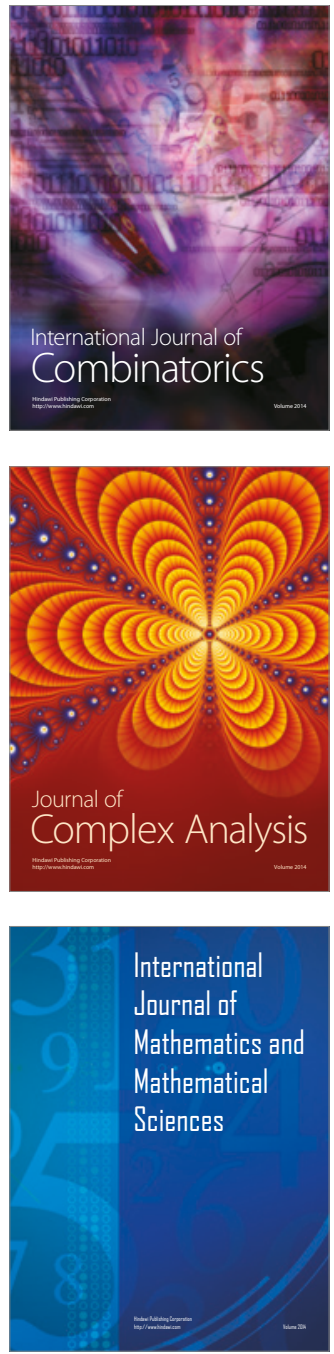
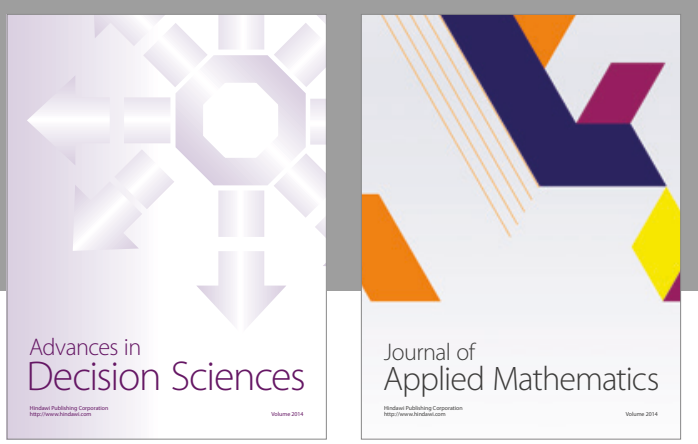

Algebra

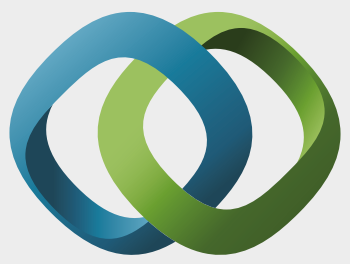

\section{Hindawi}

Submit your manuscripts at

https://www.hindawi.com
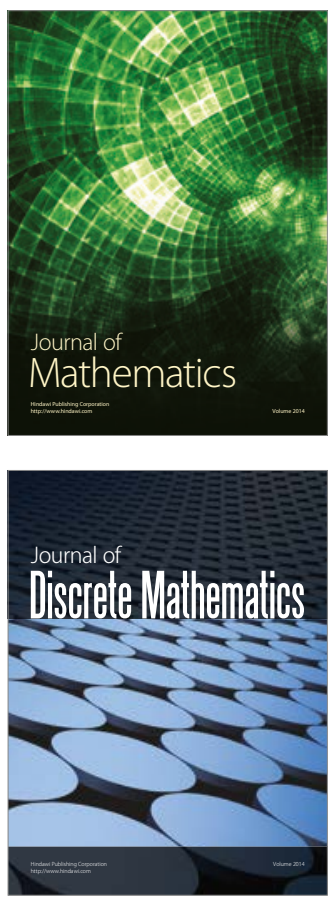

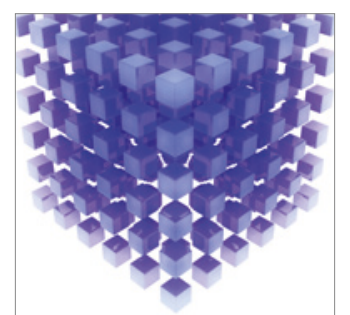

Mathematical Problems in Engineering
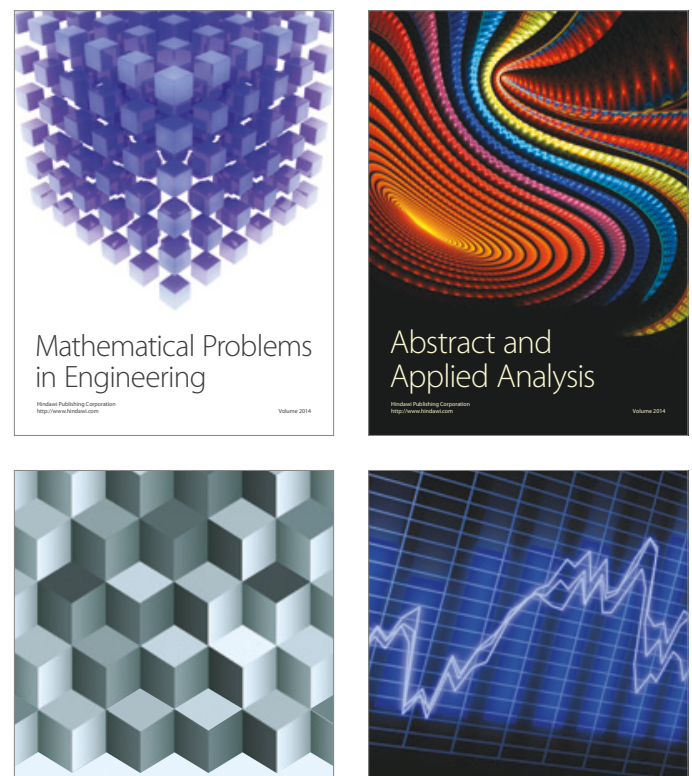

Journal of

Function Spaces

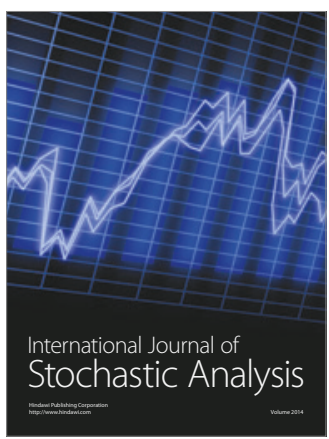

Probability and Statistics
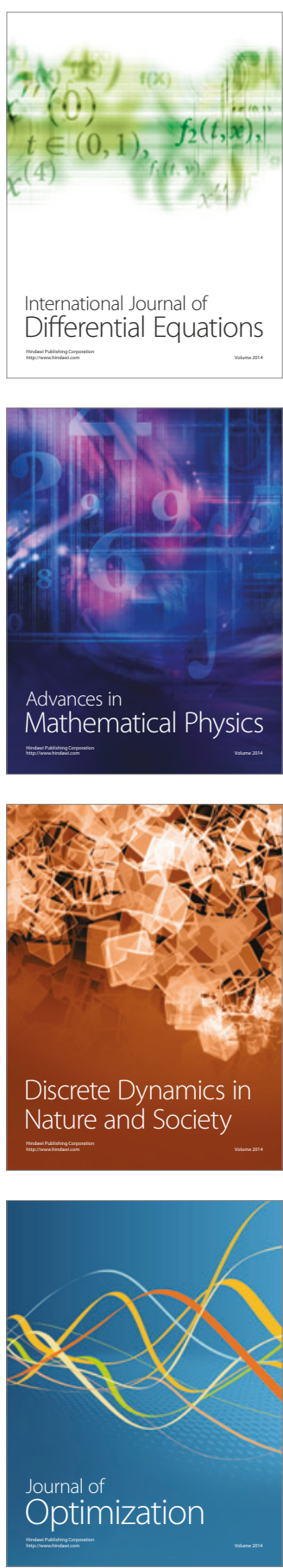